Factors predicting teachers' vocal acoustic parameters

\title{
Which teachers are most at risk for voice disorders? \\ Individual factors predicting vocal acoustic parameters monitored in situ during a workweek.
}

Short title: Factors predicting teachers' vocal acoustic parameters

\author{
Angélique Remacle ${ }^{1,2}$, Nathalie Lefèvre ${ }^{3,4}$ \\ ${ }^{1}$ Department of Speech Therapy, University of Liège, Liège, Belgium \\ ${ }^{2}$ Faculté des Sciences Psychologiques et de l’Éducation, Université Libre de Bruxelles, Brussels, Belgium \\ ${ }^{3}$ Psychological Sciences Research Institute, Université catholique de Louvain, Louvain-la-Neuve, Belgium \\ ${ }^{4}$ Louvain Institute of Data Analysis and Modeling in Economics and Statistics, Statistical Methodology and \\ Computing Service, Université catholique de Louvain, Louvain-la-Neuve, Belgium
}

Corresponding author: Angélique Remacle, $\mathrm{PhD}$

Mailing address: $\quad$ Université de Liège

Faculté de Psychologie, Logopédie et Sciences de l’Education

Département de Logopédie - Unité Logopédie de la Voix

Rue de l'Aunaie, 30 (B38)

4000 Liège (Belgium)

Phone number: $\quad$ +3243663602

Email address: $\quad$ angelique.remacle @ uliege.be 
Factors predicting teachers' vocal acoustic parameters

\begin{abstract}
Purpose: To identify the factors affecting teachers' vocal acoustic parameters, with the aim of detecting individuals at risk of phonotrauma.

Method: The voicing time, voice sound pressure level $[\mathrm{SPL}]$ and fundamental frequency $\left[f_{o}\right]$ of 87 teachers were measured during one workweek using a voice dosimeter. We retrospectively investigated the impact of 10 factors (gender, age, teaching experience, teaching level, tobacco, gastro-esophageal problems, nonoccupational voice activity, voice education, past voice problems, and biopsychosocial impact of voice problems measured using the Voice Handicap Index [VHI]) on each voice parameter.

Results: None of the above factors affected voicing time or SPL. $f_{o}$ depended significantly on gender, teaching level, nonoccupational voice activity and VHI score. Specifically, $f_{o}$ was higher in women $(\Delta=69 \mathrm{~Hz})$, in individuals without nonoccupational voice activities $(\Delta=11 \mathrm{~Hz}$ ), and in individuals with a lower VHI score (increase of $0.7 \mathrm{~Hz}$ for each additional point). For females, post hoc comparisons revealed a substantial impact of teaching level on $f_{o}$ : university instructors had deeper voices than kindergarten $(\Delta=66 \mathrm{~Hz})$, elementary $(\Delta=52 \mathrm{~Hz})$, or secondary teachers $(\Delta=41 \mathrm{~Hz})$.

Conclusions: Since higher $f_{o}$ increases the mechanical stress related to vocal fold vibration, the screening and prevention of phonotrauma should focus primarily on women, particularly those who teach at lower levels, and teachers with more self-rated voice problems. The lower $f_{o}$ of teachers who engage in nonprofessional voice activities may suggest acute inflammation or muscle fatigue due to voice overload.
\end{abstract}

Keywords: Teachers, Occupational voice, Vocal demand response, Risk factors, Voice disorders, Voice monitoring.

This is a post-peer-review, pre-copyedit version of an article published in International Archives of Occupational and Environmental Health. The final authenticated version is available online at: http://dx.doi.org/10.1007/s00420-021-01681-3 
Factors predicting teachers' vocal acoustic parameters

\section{Introduction}

\subsection{Teachers as voice users}

Teachers are occupational voice users: they work in a profession that has a higher incidence and increased risk of voice disorders (Epstein et al. 2011). They are at two to three times greater risk of voice disorders than the general population (Martins et al. 2014; Roy et al. 2004). More than half of all teachers experience a voice disorder at some point during their career (Van Houtte et al. 2011). Such problems can be devastating for their personal and professional lives, and have negative consequences for society (Van Houtte et al. 2011). Teachers' voice disorders are associated with more physical and emotional stress (Martins et al. 2014; Vertanen-Greis et al. 2018). They can lead to a decrease in teaching activities, an increase in absenteeism (Van Houtte et al. 2011), and a reassignment to administrative tasks (Martins et al. 2014; Roy et al. 2004). In addition, teachers' degraded speech signals affect schoolchildren by impairing their spoken language processing and concentration (Chui and Ma, 2019; LybergÅhlander et al. 2015; Schiller et al. 2020). Thus, society must handle the consequences of these voice problems for logistics, health care and financial costs: absent teachers must be replaced, health care is expensive, and the efficiency of the school system is negatively impacted (Epstein et al. 2011; Martins et al. 2014; Van Houtte et al. 2011).

\subsection{Framework for studying teachers' voice in situ}

Much research has focused on teachers' voice health and their occupational voice use. Such studies commonly investigate the concepts of vocal effort, vocal load, vocal loading, and vocal fatigue. Recently, a group of experts proposed a consensus description of these terms (Hunter et al. 2020). Following an extensive literature search, these experts stated that the aforementioned concepts are often confused and distinctions are blurred. To address the ambiguity of the terms vocal load and vocal loading, they proposed to use the terms vocal demand and vocal demand response. Vocal demand is the vocal requirement for a given communication scenario (e.g., teaching in a classroom), and vocal demand response is the way voice is produced by a vocalist (e.g., a teacher) in response to the perception of the communication scenario (Hunter et al. 2020).

Acoustically, vocal demand response can be quantified in terms of vocal metrics, such as

This is a post-peer-review, pre-copyedit version of an article published in International Archives of Occupational and

Environmental Health. The final authenticated version is available online at: http://dx.doi.org/10.1007/s00420-021-01681-3 
Factors predicting teachers' vocal acoustic parameters

- The voicing time, also called the time dose, which is the total time during which the vocal folds vibrate in a period. It can be expressed as a percentage ((duration of vocal fold vibration/duration of monitoring)*100);

- The voice sound pressure level (SPL, in $\mathrm{dB}$ ), which is the amount of energy of the voice sound wave;

- The fundamental frequency $\left(f_{o}\right.$, in $\left.\mathrm{Hz}\right)$, determined by the number of vocal fold cycle per second.

These three vocal acoustic parameters can be estimated over an entire day in an ecological context using voice dosimeters. On that basis, numerous studies have quantified teachers' vocal demand response over prolonged periods of time in situ (Astolfi et al. 2015; Bottalico and Astolfi 2012; Bottalico et al. 2017; Calosso et al. 2017; Cantor Cutiva et al. 2017; Hunter and Titze 2010; Masuda et al. 1993; Morrow and Connor 2011; Nusseck et al. 2018; Pirilä et al. 2017; Puglisi et al. 2017; Rantala and Vilkman 1999; Remacle et al. 2014; Sala et al. 2002; Schiller et al. 2018; Smith et al. 2017; Titze and Hunter 2015). More information on voice dosimetry and monitoring, with an emphasis on professional voice, can be found in the review by Manfredi and Dejonckere (2016).

\subsection{Conceptualization of voice injury}

To guide research on the genesis of voice disorders, it is interesting to refer to the theory developed by Haddon (1980), a leader in the field of injury epidemiology and prevention (Runyan 2003). To understand how injuries occur, the Haddon Matrix (1980) conceptualizes health problems as resulting from interactions between the host, agent, and environment (Runyan 2003). Transferred to our research area, the host is the vocalist at risk of vocal injury, the agent is the physical energy transferred to the host's vocal folds, and the environment relates to the physical and social components that contribute to injury development. Timewise, the Haddon Matrix addresses these components at three different phases of influence: before, during, and after the injury occurs.

Among teachers as hosts, high vocal demand has repeatedly been identified as a major risk factor for voice disorders such as fatigue, dysphonia, and laryngeal injury (Epstein et al. 2011; Hunter et al. 2020; Manfredi and Dejonckere 2016; Martins et al. 2014; Roy et al. 2004; Van Houtte et al. 2010; Vilkman 2004). The agent of injury is mechanical: phonation triggers mechanical stress on the vocal folds, including oscillation, collision, friction, contraction, deformation, elongation, and acceleration (Titze 2000). The longer the voicing time, the greater the stress applied on the tissue. The voice SPL is related to the amplitude of vocal fold vibration and $f_{\mathrm{o}}$ is associated with 
Factors predicting teachers' vocal acoustic parameters

their vibration rate. $f_{\mathrm{o}}$ is regulated by the combined action of laryngeal muscles and subglottal pressure. The adjustment of laryngeal muscles influences the vocal folds' length, stiffness (muscle or tissue), and vibrating mass, and therefore their vibration frequency (Titze 2000). Subglottal pressure influences both the vibration amplitude of the vocal folds, affecting voice SPL, and their tension, affecting vibration frequency. It is commonly accepted that excessive mechanical loads lead to tissue damage, that is, phonotrauma. Many authors have emphasized the link between excessive vibration patterns and voice disorders (Epstein et al. 2011; Manfredi and Dejonckere 2016; Martins et al. 2014; Roy et al. 2004; Van Houtte et al. 2010; Vilkman 2004). In teachers, phonotraumatic lesions, which develop from excessive or inappropriate vocal patterns, are most commonly observed through videolaryngoscopic examinations (Martins et al. 2014).

With regard to the environment, the school context plays a critical role. Teachers have been found to speak longer and louder than other workers (Masuda et al. 1993; Sala et al. 2002). Their voicing time at work is twice as long as in non-working situations (Hunter and Titze 2010; Remacle et al. 2014). In addition, they speak louder and at a higher pitch at school (Hunter and Titze 2010; Titze and Hunter 2015). On average, their vocal folds can run a fivekilometer race and collide up to 2 million times in a teaching day (Titze and Hunter 2015). Several environmental factors increase the likelihood of vocal injury, such as dust, vapor, variations in temperature, dryness, and/or excessive humidity (de Jong 2010; Vilkman 2004). Voice dosimetry research has shown that environments with poor acoustics, inadequate reverberation time (Astolfi et al. 2015; Calosso et al. 2017), and high background noise (Calosso et al. 2017; Pirilä et al. 2017; Puglisi et al. 2017; Schiller et al. 2018) increase teachers' vocal load. A greater distance between speaker and listener also leads to extra phonatory effort by the speaker (Vilkman 2004).

In sum, teachers' voice-related injuries are undoubtedly the result of interactions between the three components (host, agent, and environment) identified in the Haddon Matrix (1980). The remainder of this introduction and the study itself focus on factors related to the host and his/her personal characteristics that represent potential agents of injury.

\subsection{Factors influencing vocal demand response}

According to Hunter et al. (2020), vocal demand response depends on individual attributes, which may partially explain the disparate vocal injuries in vocalists facing a similar vocal demand. Given the scenario of a workday, Remacle et al. (2018) evaluated the inter- and intra-subject variability of teachers' responses to vocal demand in terms of vocal acoustic parameters measured at the beginning and at the end of 66 teaching days. They This is a post-peer-review, pre-copyedit version of an article published in International Archives of Occupational and

Environmental Health. The final authenticated version is available online at: http://dx.doi.org/10.1007/s00420-021-01681-3 
Factors predicting teachers' vocal acoustic parameters

established a typology including three different types of response. The first was characterized by a substantial $f_{\mathrm{o}}$ increase from morning to evening, interpreted as a common, appropriate adaptation to increased vocal requirement. The second response pattern showed increases in $f_{\mathrm{o}}$ and harmonics-to-noise ratio, and decreases in jitter and shimmer, interpreted as a shift to hyperfunctional voice production. The third response type comprised decreases in $f_{\mathrm{o}}$ and harmonics-to-noise ratio and increases in jitter and shimmer, suggesting acute tissue inflammation or muscle fatigue following the workday.

These different response patterns may rely on (1) individual factors known to interfere with vocal health such as gender, age, and voice education; (2) other potential agents of injury referred to as inflammatory influences; and (3) individual tissue's ability to withstand biomechanical energy transfer during voicing. The influencing factors considered in this study and their potential impact on teachers' vocal acoustic parameters measured in situ are presented in the following paragraphs.

Gender. For an equal amount of voicing, women's higher fundamental frequency results in more vocal fold oscillations and collisions than men's. Voice dosimetry in teachers has shown higher voice $f_{o}$, slightly higher voicing percentage and louder voice in females than in males (Hunter and Titze 2010). This has been claimed to partially explain the increased risk of voice disorders in female versus male teachers (Hunter et al. 2011; Roy et al. 2004).

Age and teaching experience. Speaking fundamental frequency becomes lower with age, particularly in women (Nishio and Niimi 2008). Age and teaching experience also affect teachers' vocal behavior (Roy et al. 2004). Monitoring of elementary teachers' voices has shown that the more teaching experience an individual has, the higher the voicing percentage is (Puglisi et al. 2017). Additionally, ambulatory monitoring of primary school teachers has indicated a decrease in their voice $f_{\mathrm{o}}$ and SPL with age (Bottalico and Astolfi 2012). These authors attribute the decrease in voice intensity to a reduction in respiratory ability with age, while the lowering of $f_{\mathrm{o}}$ is due to a progressive thickening of the vocal fold epithelium.

Teaching level. So far, studies have produced varying results regarding the impact of teaching level: some indicate a greater prevalence of voice disorders at lower levels (Munier and Kinsella, 2008; Preciado et al. 1998), while others show no connection between voice disorders and teaching level (Kooijman et al. 2006, 2007). Using voice monitoring over one workweek, Remacle et al. (2014) compared vocal parameters and vocal doses of 12 kindergarten and 20 elementary school teachers, all female. They found higher cycle doses (approximation of the total glottal cycles over time, based on voicing time and $f_{\mathrm{o}}$ ) and distance doses (approximation of the distance 
Factors predicting teachers' vocal acoustic parameters

traveled by the vocal folds, based on voicing time, $f_{\mathrm{o}}$ and amplitude) for kindergarten teachers. Nusseck et al. (2018) monitored voice SPL, $f_{\mathrm{o}}$, and voicing time in 118 student teachers at elementary, junior high, secondary and special schools. During a typical classroom lesson, these parameters did not differ between teaching levels. However, the lower the level, the louder the background noise in classrooms.

Inflammatory influences. Smoking influences the microstructure of the vocal folds (Kelleher et al. 2014) and therefore voice acoustics and self-rated voice complaints (Ayoub et al. 2019). Compared to nonsmokers, cigarette smokers' $f_{\mathrm{o}}$ is lower and they experience more voice complaints (Ayoub et al. 2019). Teachers in general are less likely to use tobacco products than the general population, yet they still report more voice disorders (Roy et al. 2004).

Gastro-esophageal problems are additional risk factors for occupational voice disorders (Manfredi and Dejonckere 2016). In teachers, rush-related eating habits may favor gastrointestinal disorders, especially reflux, identified as a cause of acid laryngitis (Martins et al. 2014). Such chronic inflammation of the larynx might result in a lower voice $f_{\mathrm{o}}$. According to the systematic review by Lechien et al. (2017), the consequences of laryngopharyngeal reflux encompass modifications of voice quality (mostly hoarseness) and modifications of acoustic parameters (i.e., impaired indicators of vibration stability and decreased signal-to-noise ratio, but no $f_{\mathrm{o}}$ or SPL change).

Voice-related factors. Voice education, in the form of training of the speaking or singing voice, might represent a protective factor against voice disorders as it is supposed to strengthen vocal technique. Although voice training is recognized as a direct method of primary prevention in professional voice users, few teachers are given such training (Hazlett et al. 2011). In their review of 10 studies investigating the impact of voice training in professional voice users, Hazlett et al. (2011) found no conclusive evidence of effects on acoustic parameters such as $f_{\mathrm{o}}$ or SPL. However, training improves voice awareness and knowledge, which may then protect against vocally abusive behaviors.

Additionally, several studies that monitored teachers' voices examined the differences between occupational and nonoccupational settings (Hunter and Titze, 2010; Remacle et al. 2014; Schiller et al. 2018). Although vocal load is clearly heavier at work, Hunter and Titze (2010) stress that nonoccupational voice use not only leaves little time for vocal rest but also adds more vocal load to an already overloaded voice. Nonoccupational voice use includes after-school communication, at home or during leisure, social, or community activities. The nonoccupational voice 
Factors predicting teachers' vocal acoustic parameters

activities referred to hereafter include weekly vocally demanding hobbies such as singing, theater, leading a youth club, coaching sports, and leading meetings.

Finally, researchers have tracked the vocal demand response of healthy and pathological speakers using dosimetry to better understand the patterns that promote voice disorders. For instance, Van Stan et al. (2015) compared the voice use profiles of 35 women with nodules or polyps and of matched controls. Similarly, Szabo Portela et al. (2018) compared female patients with voice-intensive occupations (10 with phonasthenia and 10 with nodules) and vocally healthy colleagues. In both studies, average vocal acoustic measures did not differ between the patients and their matched controls.

\subsection{Study objectives}

Previous research has established that teachers' high vocal demand, quantifiable through vocal acoustic metrics, is associated with an increased likelihood of voice disorders. Mediators can intervene and the impact of several influencing factors has been considered in isolation. The objective of this study was to determine whether a large set of factors considered together can (1) predict vocal demand response through vocal acoustic parameters measured in situ during one workweek, and (2) help to identify teachers who are most at risk of phonotrauma. To our knowledge, no study has analyzed such a vast database of teachers' voice use to investigate the impact of several factors together, namely gender, age, teaching experience, teaching level, tobacco consumption, gastro-esophageal problems, nonoccupational voice activity, voice education, past voice problems, and biopsychosocial impact of voice problems. We hypothesized that each factor would influence teachers' voice use through at least one vocal parameter monitored over the workweek.

\section{Method}

\subsection{Participants}

This retrospective study relies on a database resulting from the first author's research work. From 2010 to 2017, data were collected from 90 teachers in the French community in Belgium. The data collection took place in five kindergartens, seven elementary schools, nine secondary schools, and one university. For each participant, the database includes voice ambulatory measures over one workweek, individual information collected with questionnaires, and daily self-evaluations of voice.

This is a post-peer-review, pre-copyedit version of an article published in International Archives of Occupational and Environmental Health. The final authenticated version is available online at: http://dx.doi.org/10.1007/s00420-021-01681-3 
Factors predicting teachers' vocal acoustic parameters

Recruitment procedure. After obtaining approval from the local research ethics committee and authorizations from the schools' principals, teachers were informed orally and by letter of the study. An individual meeting with each teacher who volunteered enabled us to explain the study's objectives and procedures. Each participant signed a consent form before being enrolled in the study. All procedures were in accordance with the 1964 Helsinki Declaration. No information was collected on the response rate.

Inclusion criteria for this study. Out of the 90 participants in our database, only teachers without a known voice pathology at the time of data collection were included. Voice status was based on questionnaires completed by the participants and perceptual evaluations carried out by the first author assisted by a final-year graduating student in speech therapy. Based on connected speech, the purpose of the perceptual evaluation was to state whether the voice quality was normal or abnormal. No laryngeal examination was performed when setting up the database. Based on their responses to questionnaires, three participants from the database were excluded from this study because they reported voice pathologies diagnosed before their recruitment: two females with vocal fold nodules and one female with superior laryngeal nerve injury. None of the participants included had a history of vocal fold lesions or surgery on the vocal folds. One teacher had had speech therapy in the past to improve her voice use. She was included in the sample because she reported being cured of this pathology at the time of the study. The final sample comprises 87 teachers (66 women and $21 \mathrm{men})$. The mean age of the sample is 40 years $(\min =23 ; \max =63)$. The mean age is 39 years for females $(\min =23 ; \max =63)$ and 40 years for males $(\min =24 ; \max =56)$.

\subsection{Material and data collection}

\subsubsection{Evaluation of influencing factors}

Individual data were collected using questionnaires that the participants completed before their week of voice monitoring. A summary of each teacher's individual characteristics is supplied in the supplemental material and an overview of the influencing factors according to gender is presented in Table 1. The sample can be described as follows according to the factors examined.

The mean teaching experience is 15 years $(\min =1$; $\max =36)$. Regarding teaching level, the sample includes 21 kindergarten teachers (teaching children from 2.5 years old), 20 elementary schoolteachers (teaching children from 6 years old), 35 secondary schoolteachers (teaching students from 12 years old), and 11 university instructors (teaching students from 18 years old).

This is a post-peer-review, pre-copyedit version of an article published in International Archives of Occupational and Environmental Health. The final authenticated version is available online at: http://dx.doi.org/10.1007/s00420-021-01681-3 
Factors predicting teachers' vocal acoustic parameters

Ten participants consumed tobacco daily. Their consumption ranged from 1 to 30 cigarettes per day. Fifteen participants had experienced gastro-esophageal problems, such as gastro-esophageal reflux, esophagitis, gastric ulcer, irritable bowel syndrome or hiatus hernia.

Twenty participants engaged in a nonoccupational voice activity at least once a week. Among them, 7 females and 4 males sang, 2 females were involved in theater, 1 male led a youth club, 4 females and 1 male were sports coaches or instructors outside school hours (e.g., aerobics, swimming, volleyball or track coaching), and one male led extra-professional meetings.

For the purposes of this study, voice education is considered to mean having received weekly speaking (elocution, theater, or dramatic arts) and/or singing voice training for at least one year. According to this definition, 22 participants had received voice education. Five females and 3 males had received speaking voice education, 9 females and 2 males had had singing voice education, and 2 females and 1 male had had both speaking and singing voice education.

Regarding self-rated voice problems, 29 teachers reported having experienced a voice disorder in the past. In most cases, this had involved episodes of aphonia. Finally, the biopsychosocial impact of voice problems at the time of the study was measured with the French version of the Voice Handicap Index (VHI) (Woisard et al. 2004). This questionnaire is made up of 30 items. Each item is scored on a 5-point scale from 0 (never) to 4 (always). The total score ranges from 0 to 120 . Low scores indicate few complaints and high scores indicate many complaints. The mean VHI score for the sample was $11.6(\min =0 ; \max =40)$.

<Table 1 about here>

\subsubsection{Monitoring of vocal acoustic parameters}

Phonatory behavior was quantified using the Ambulatory Phonation Monitor (APM), model 3200 (KayPENTAX, Montvale, NJ). Each participant wore the device over five full days of normal activities in a typical workweek (Monday to Friday).

The APM is a portable voice dosimeter that incorporates an accelerometer, that is, a throat sensor mounted on a silicon pad attached to the participant's neck with medical glue. Gluing the accelerometer prevents any movement between the sensor and the skin. The accelerometer is connected to a microprocessor carried in a waist pack. Every $50 \mathrm{~ms}$, the accelerometer estimates vocal SPL and $f_{o}$ from skin acceleration level due to the vocal fold vibration. According the APM specifications, the $f_{o}$ is estimated using an autocorrelation algorithm, with This is a post-peer-review, pre-copyedit version of an article published in International Archives of Occupational and

Environmental Health. The final authenticated version is available online at: http://dx.doi.org/10.1007/s00420-021-01681-3 
Factors predicting teachers' vocal acoustic parameters

measurement errors not greater than $\pm 1 \mathrm{~Hz}$. The bandwidth ranges from $2 \mathrm{~Hz}$ to $3000 \mathrm{~Hz}$, with a flatness of $\pm 1.5 \mathrm{~dB}$ in the frequency range 50-1000 Hz. Regarding the uncertainty of the estimated parameters, the APM tends to overestimate the calculation of both mean SPL (mean error $=1.15 \pm 1.01 \mathrm{~dB}$ ) and mean $f_{\mathrm{o}}$ (mean error $=2.9 \pm 2.45$ Hz) (Bottalico et al. 2018).

The voicing decision and subsequently the voicing time calculation were based on a $50-500 \mathrm{~Hz}$ frequency range and a 30-130 dB SPL range: occurrences within these ranges were considered as voicing while other occurrences were considered not to be voicing. Similar frequency and SPL ranges have been used previously (Remacle et al. 2014) and are the default ranges of the APM software. At the onset of each workday, the dosimeter was installed and calibrated according to the APM instruction manual (KayPENTAX, 2009), in a quiet room within each participant's school. The throat sensor calibration was intended to relate the amplitudes of the throat sensor accelerometer signal and the voice SPL signal measured at $15 \mathrm{~cm}$ from the mouth using a reference microphone. The participant was instructed to take a deep breath and sustain the vowel /a/ from the softest to the loudest voice for about 10 seconds. When gliding from soft to loud was not possible, the participant was instructed to produce several shorter instances of /a/ in a soft, medium, and loud voice with a breath after each production. As the participant phonates, the software displays the calibration data points and a straight line representing the linear correlation between the SPL of the microphone signal and the amplitude of the throat sensor signal. The calibration screen shows a line after at least seven data points have appeared. If the line has a low coefficient of determination, the calibration is not valid (Bottalico et al. 2018). In this study, we stopped the calibration after 10 seconds of voice production. Whenever the software had not collected adequate phonation data and instructed us to recalibrate, we did so.

After each monitoring period, data were downloaded onto a computer using the APM software. For each day, raw data were exported as a .csv file. In total, five days of monitoring were extracted for each of the 87 teachers, resulting in 435 days. Since four files proved to be unusable, the final analysis covers 431 days. To allow for further analyses using SPSS, these 431 days were compiled in a single .sav file. To enable us to use this file, we reduced its size by keeping one out of every four data points (i.e., we kept one data point every $200 \mathrm{~ms}$ and simply removed the other three data points). Based on five days of monitoring of the first participant, we checked whether the $f_{\mathrm{o}}$, SPL, and voicing time measures varied between the complete file (data points every $50 \mathrm{~ms}$ ) and the reduced file (data points every $200 \mathrm{~ms}$ ), by calculating the relative error (RE) of the means and SDs using the following formula:

This is a post-peer-review, pre-copyedit version of an article published in International Archives of Occupational and Environmental Health. The final authenticated version is available online at: http://dx.doi.org/10.1007/s00420-021-01681-3 
Factors predicting teachers' vocal acoustic parameters

$$
R E=\frac{\mid \text { value for data points every } 50 \mathrm{~ms}-\text { value for data points every } 200 \mathrm{~ms} \mid}{\text { value for data points every } 50 \mathrm{~ms}}
$$

The very small RE obtained for the means $\left(f_{\mathrm{o}}=.0002\right.$; SPL $=.0002$; voicing time $\left.=1.8^{*} 10^{-5}\right)$ and SDs $\left(f_{\mathrm{o}}=.001\right.$; SPL $=.002$; voicing time $=9.6^{*} 10^{-6}$ ) reassured us regarding our decision to use one data point every $200 \mathrm{~ms}$.

Overall, the statistical analyses cover 4,479 hours of voice monitoring with one data point every $200 \mathrm{ms,}$ corresponding to 18,000 data points per hour.

Supplemental material shows the total duration of monitoring, mean voicing percentage, voice $f_{o}$ and SPL for each participant during the workweek.

\subsection{Statistical analysis}

Statistical processing was performed with SPSS Statistics for Windows (Version 25.0. Armonk, NY: IBM Corp.). All the calculations were performed considering a confidence interval (CI) of 95\%. The significance level was set at .05 .

To investigate the potential relationships between the influencing factors that will later be used in the statistical models, we first tested the existence of pairwise associations (see Table 2). Pearson chi-square tests examined the link between the categorical variables two by two. One-way ANOVAs were used to test the link between one continuous variable and one categorical variable. Pearson correlations were applied to test the relationship between two continuous variables. In addition, the links between the vocal acoustic parameters measured every $200 \mathrm{~ms}$ were tested using Pearson correlations (see supplemental material).

Next, to determine the effect of influencing factors on the vocal acoustic parameters, general linear mixed models (GLMMs) were used. The term "mixed" refers to the use of both fixed and random effects in the same model. Compared to traditional approaches such as ANOVAs, the advantage of mixed models is that they take into account all the data points of the vocal parameters (i.e., repeated measures every $200 \mathrm{~ms}$ for 5 days), instead of the means. A statistical model was constructed for each vocal acoustic parameter. Voicing time, SPL and $f_{o}$ (dependent variables, continuous) are predicted by 10 influencing factors (independent variables) in their respective models. Independent variables include gender $(0=$ female, $1=$ male $)$, age (in years), teaching experience (in years), teaching level $(1=$ kindergarten, 2 = elementary, 3 = secondary, 4 = university), tobacco use (yes or no), gastro-esophageal problems (yes or no), nonoccupational voice activity (yes or no), voice education (yes or no), past voice problems (yes or no), and biopsychosocial impact of voice problems (VHI score). For each significant effect $(p<.05)$ of an 
Factors predicting teachers' vocal acoustic parameters

independent variable on a vocal parameter, the associated F-test value and p-value are reported. Table 3 shows the associated t-test value and p-value, degrees of freedom (df), estimates (E), standard errors and 95\% CIs. The estimates indicate the direction of the relationship between two variables. The 95\% CIs indicate the magnitude of the effect in addition to the statistical significance provided through the p-value (Lee 2016). For post hoc comparisons of teaching levels, pairwise comparisons of means were performed using Holm's sequential Bonferroni procedure. The applicability of the analyses was checked in advance. Residual analysis for the models reported shows that the validity conditions were respected, and particularly homoscedasticity and normality.

\section{Results}

\subsection{Relationships between the influencing factors}

Table 2 presents statistics concerning the relations between the factors.

In this data set, there is a significant association between gender and teaching level. Table 1 shows the breakdown of participants according to gender for each teaching level.

The strong positive correlation between age and teaching experience (see Table 2) indicates that the older teachers are, the more teaching experience they have.

There is a negative correlation between self-rated voice complaints and age (see Table 2): the older teachers are, the lower their VHI score is.

There is a negative correlation between self-rated voice complaints and teaching experience (see Table 2): the more experience teachers have, the lower their VHI score is.

The one-way ANOVA shows that teachers who report past voice problems have higher VHI scores than those who report never having had a voice problem (VHI scores: mean $=16.1, \mathrm{SD}=10.4$, and mean $=9.3, \mathrm{SD}=9.3$ respectively).

$<$ Table 2 about here>

\subsection{Relationships between the vocal acoustic parameters}

For each participant, the correlations between the $f_{o}$, SPL, and voicing time measured every $200 \mathrm{~ms}$ are presented in the supplemental material. All the participants show a positive correlation between $f_{o}$ and SPL. The summary across participants indicates weak to strong positive correlation between voice $f_{o}$ and SPL $(\mathrm{r}$ median $=$ .496 ; $\min =.164 ; \max =.638$ ). Correlations between voicing time and $f_{o}$ are weak to null, with variability across

This is a post-peer-review, pre-copyedit version of an article published in International Archives of Occupational and Environmental Health. The final authenticated version is available online at: http://dx.doi.org/10.1007/s00420-021-01681-3 
Factors predicting teachers' vocal acoustic parameters

participants $(\mathrm{r}$ median $=-.010 ; \min =-.224 ; \max =.219)$. Similarly, weak to null correlations are observed between voicing time and SPL, with variability across participants $(\mathrm{r}$ median $=-.090 ; \min =-.273 ; \max =.284)$.

\subsection{Factors predicting vocal acoustic parameters}

According to the voicing time and SPL models, none of the examined factors influences the amount of voicing or voice SPL (see Table 3). However, the $f_{o}$ model shows that several factors have a significant impact on teachers' fundamental frequency.

More specifically, gender has a significant impact on $f_{o}(F(1,74)=132.1 p<.001)$. The estimate $(\mathrm{E}=69$; 95\% CI 56.7- 80.4) expresses the contrast between the female participants and the male participants: women's mean $f_{o}$ is $69 \mathrm{~Hz}$ higher than men's. Table 4 shows means for $f_{o}$ according to gender.

VHI score has a significant effect on $f_{o}(F(1,74)=8.95, p=.004)$ : for each additional point, $f_{o}$ increases by $0.7 \mathrm{~Hz}(95 \%$ CI $0.2-1.2)$ (see Table 3).

Engagement in a vocally demanding nonoccupational activity has a significant effect on $f_{o}(F(1,74)=4.34$, $p=.041$ ): teachers who use their voices nonoccupationally have an $f_{o}$ that is $11 \mathrm{~Hz}$ lower (95\% CI 0.5-21.3) (see

Table 3). Table 4 presents the means for $f_{o}$ according to nonoccupational voice activity for males and females.

Teaching level has a significant effect on $f_{o}(F(3,74)=12.49, p<.001)$. To compare $f_{o}$ for each pair of teaching levels, a post hoc pairwise comparison of means was done, with a sequential Bonferroni correction (see Table 5). These results suggest that $f_{o}$ decreases as teaching level increases in the overall sample. However, gender was found to influence teaching level (see Table 2): the lower the level, the higher the proportion of females. Table 1 shows that our sample is made up exclusively of females at the kindergarten and elementary school levels. Because gender is a confounding factor, we subsequently created two separate models investigating $f_{o}$ : one for males and one for females.

$<$ Tables 3, 4 and 5 about here>

When the analysis covers only men, teaching level has no effect on $f_{o}(F(1,11)=0.336, p=.574)$. When the analysis covers only women, teaching level has a significant impact on $f_{o}(F(3,54)=14.02, p<.001)$. Post hoc pairwise comparisons of means with a sequential Bonferroni correction (see Table 5) show that female kindergarten teachers have a mean $f_{o} 13 \mathrm{~Hz}$ higher than elementary school teachers (95\% CI -5.2-31.7), $25 \mathrm{~Hz}$ higher than secondary teachers (95\% CI 6.4-43.4) and $66 \mathrm{~Hz}$ higher than university instructors (95\% CI 36.7-94.6). Elementary This is a post-peer-review, pre-copyedit version of an article published in International Archives of Occupational and

Environmental Health. The final authenticated version is available online at: http://dx.doi.org/10.1007/s00420-021-01681-3 
Factors predicting teachers' vocal acoustic parameters

teachers have a mean $f_{o} 12 \mathrm{~Hz}$ higher than secondary teachers (95\% CI -6.6-30) and $52 \mathrm{~Hz}$ higher than university instructors (95\% CI 24.2-80.6). Finally, secondary school teachers have a mean $f_{o} 41 \mathrm{~Hz}$ higher than university instructors (95\% CI 12.6-68.8). Table 4 shows the means for $f_{o}$ according to teaching level.

\section{Discussion}

\subsection{Relationships between the influencing factors}

The main purpose of this study was to identify the factors that influence teachers' voice use in real-life situations during one workweek. When one studies the effect of influencing factors on vocal acoustic parameters, it is important to strictly control the links among those factors. In our sample of teachers from kindergarten, elementary school, secondary school and university, we found a significant correlation between gender and teaching level: the lower the teaching level, the more female-dominated the profession is, which is representative of the teaching population in general. To take this into consideration, further analyses examined the effect of teaching level with separate statistical models for women and men.

As expected, there is a significant association between age and teaching experience: an older teacher is likely to have more experience than a young teacher. There is a negative correlation between the biopsychosocial impact of voice problems and both age and teaching experience: the higher the VHI score, the more likely teachers are to be young and inexperienced. To explain these data, two hypotheses can be formulated. First of all, experience may have a protective effect: the better VHI in older, more experienced teachers may be due to learning of compensatory habits or techniques to minimize voice problems (Thibeault 2004). Secondly, the "healthy worker effect" may apply: teachers who have voice disorders may leave the profession earlier (Thibeault 2004) to take early retirement or change professions, which would leave a sample made up exclusively of teachers without voice disorders.

Finally, there is a significant association between a history of past voice problems and the biopsychosocial impact of voice problems at the time of the study. Worse VHI scores in individuals who have previously had voice complaints suggest that teachers' voice problems may become chronic.

This is a post-peer-review, pre-copyedit version of an article published in International Archives of Occupational and Environmental Health. The final authenticated version is available online at: http://dx.doi.org/10.1007/s00420-021-01681-3 
Factors predicting teachers' vocal acoustic parameters

\subsection{Relationships between the vocal acoustic parameters}

The positive correlation between the ambulatory measures of $f_{\mathrm{o}}$ and SPL confirms previous long-term monitoring findings (Hunter and Titze 2010). From the physiological point of view, the link between voice frequency and intensity is well known: the voice gets louder with increased lung pressure and with higher pitch (Titze, 2000).

The absence of a clear link between voicing time, on one hand, and voice $f_{\mathrm{o}}$ and SPL, on the other, might be due to the variability of the teachers' response to vocal demand. The changes in the voice acoustic parameters following a workday are teacher-specific (Remacle et al. 2018).

\subsection{Factors predicting vocal acoustic parameters}

Using GLMMs, the voicing time, vocal SPL and fundamental frequency of 87 teachers monitored for one workweek were studied in light of 10 factors (gender, age, teaching experience, teaching level, tobacco consumption, gastro-esophageal problems, nonoccupational voice activity, voice education, past voice problems, and biopsychosocial impact of voice problems at the time of the study).

Based on the results of the voicing time and SPL statistical models, none of these factors predicts teachers' amount of voicing and vocal SPL. However, the $f_{o}$ model showed that gender, teaching level, VHI score and nonoccupational voice activities can predict teachers' fundamental frequency.

As established in the literature, we found a significant effect of gender on $f_{o}$. Throughout their daily activities, female teachers' mean speaking $f_{o}(=224.5 \mathrm{~Hz})$ is $69 \mathrm{~Hz}$ higher than that of their male colleagues $(=155.9$ Hz). Similar differences have been found in other studies that monitored teachers' voices over long durations (Bottalico and Astolfi 2012; Hunter and Titze 2010). Gender-specific anatomo-physiological differences explain women's higher $f_{o}$, which makes them more vulnerable to phonotrauma due to the increased vocal fold oscillations and collisions for a similar amount of voicing (Hunter et al. 2011).

As for voicing time and SPL, no gender-based difference was measured. Similarly, Bottalico and Astolfi (2012) did not see any significant effect of gender on voicing time percentage and vocal SPL in elementary schoolteachers. Nusseck et al. (2018) also found no difference based on gender in elementary and secondary teachers starting their careers. Hunter and Titze (2010) found a trend toward female teachers speaking louder and longer. To date, voice dosimetry studies have not statistically confirmed the belief that women have higher voicing percentages

This is a post-peer-review, pre-copyedit version of an article published in International Archives of Occupational and Environmental Health. The final authenticated version is available online at: http://dx.doi.org/10.1007/s00420-021-01681-3 
Factors predicting teachers' vocal acoustic parameters

than men. Nevertheless, Nusseck et al. (2018) found greater differences between noise SPL and voice SPL for male teachers than for female teachers, suggesting that the men covered background noise more.

A crucial finding of this study is that teaching level has a significant impact on fundamental frequency for women. The absence of male participants at the kindergarten and elementary school levels may have prevented us from detecting differences based on teaching level in men. For women - who are represented at all teaching levels in our sample but in only a small number at the university level - the lower the grades they teach, the higher-pitched their speaking voice. The difference between the lowest and the highest level is $66 \mathrm{~Hz}$. There are several possible explanations of this phenomenon. First, it may be due to the Lombard effect, which automatically causes speakers to increase their voice SPL and $f_{\mathrm{o}}$ in noisy environments (for a review, see Yiu and Yip 2016). Higher noise levels have been measured in teaching establishments for lower grades (Nusseck et al. 2018) and for younger groups, where noise is frequently attributed to student activities (Picard and Bradley 2001). However, our data do not show any increase in voice SPL in teachers at lower levels. Secondly, it could be the convergence effect, defined as adults' tendency to imitate some acoustic-phonetic characteristics of another speaker's speech to facilitate communication by establishing common perceptuo-motor ground between speakers (Sato et al. 2013). This automatic phenomenon would explain a tendency for teachers to imitate the acoustic characteristics of their students' voices, particularly fundamental frequency (Remacle et al. 2014). Given that children's $f_{o}$ decreases with age, teachers of lower grades would adopt a higher-pitched voice in the workplace. Thirdly, the phenomenon may be due to some characteristics of child-directed speech, defined as the spontaneous way in which adults speak with infants and young children (SaintGeorges et al. 2013). The higher $f_{o}$ and greater $f_{o}$ variability of speech directed to children (Saint-Georges et al. 2013) may contribute to teachers at lower teaching levels adopting a higher-pitched voice. Fourthly, greater $f_{o}$ values for these teachers may be related to occupational stress. Previous studies have shown that the lower the teaching level, the higher the stress (Agai-Demjaha et al. 2015; Malik et al. 1991). According to the Model for Voice and Effort (Van Puyvelde et al. 2018), increased $f_{o}$ is a response to stress in the form of cognitive and/or emotional load. Finally, speaking with a lower-pitched voice could be an adaptation to assert authority in classrooms with older students. In summary, the lower the teaching level, the higher the female teachers' $f_{\mathrm{o}}$ and consequently the greater the risk of potential tissue damage due to mechanical load. In point of fact, lower grades have often been associated with more voice problems (Martins et al. 2014; Munier and Kinsella 2008; Preciado et al. 1998). Apart from fundamental

This is a post-peer-review, pre-copyedit version of an article published in International Archives of Occupational and Environmental Health. The final authenticated version is available online at: http://dx.doi.org/10.1007/s00420-021-01681-3 
Factors predicting teachers' vocal acoustic parameters

frequency, our findings show no effect of teaching level on voicing time or vocal SPL, which matches the conclusions of other dosimetry studies (Nusseck et al. 2018; Remacle et al. 2014).

Contrary to the assumption that previous voice education might prevent abusive vocal behaviors such as speaking for long durations, with high voice SPL and $f_{\mathrm{o}}$, teachers who had received such training did not show different vocal parameters than those who had not. The data do not reveal different ambulatory voice patterns in situ for teachers who had had speaking and/or singing voice training. However, longitudinal randomized control trials would be worthwhile to determine whether voice education has an effect on teachers' daily-life vocal acoustic parameters.

Of the 87 participants, 15 women and 5 men engaged weekly in a nonoccupational activity where they were likely to project their voice, such as singing, theater, coaching sports, and leading a youth club or meetings. This had a significant effect on their voice frequency measured over the week, since these teachers' mean $f_{o}$ was $11 \mathrm{~Hz}$ (or 1.7 semitones) lower than that of the others. In their typology of teachers' vocal demand response, Remacle et al. (2018) identified three patterns. Regarding the frequency changes from morning to evening, the first and second patterns were both characterized by an $f_{o}$ increase, interpreted respectively as an appropriate adaptation to vocal demand and as a change to a hyperfunctional voice. In contrast, the third response pattern was characterized by an $f_{o}$ decrease, suggesting acute inflammation or muscle fatigue following the workday. Although this is not statistically significant, our teachers with a nonoccupational voice activity also had an average voicing time $1 \%$ higher than others (see Table 3). In addition to occupational voicing time, earlier studies have measured a nonoccupational voicing percentage in teachers ranging from 10\% to 15\% (Hunter and Titze, 2010; Remacle et al. 2014). As Hunter and Titze (2010) point out, this nonoccupational voice use is noteworthy, as it represents an additional burden for an already overloaded voice and may also impede vocal recovery. In light of these studies, the lower frequency in teachers who have a vocally demanding nonoccupational activity may be due to excessive mechanical stress, leading to tissue inflammation or muscle fatigue.

Logically, we could expect that teachers who reported past and present voice complaints would use their voice in a more phonotraumatic way, including speaking longer, with an increased voice SPL and $f_{\mathrm{o}}$. Statistical analyses reveal that self-reported past and current voice problems are not associated with an increase in ambulatory measures of voicing time or voice level. However, teachers who self-report more voice complaints have higherpitched voices: for each additional point on the VHI score, $f_{\mathrm{o}}$ rises by a mean $0.7 \mathrm{~Hz}$. This phenomenon is not 
Factors predicting teachers' vocal acoustic parameters

directly caused by gender since VHI score does not differ significantly between men (mean $=12.7, \mathrm{SD}=9.1$ ) and women $($ mean $=11.2, \mathrm{SD}=10.5)$. More voice complaints associated with higher fundamental frequency may indicate increased laryngeal tension (Remacle et al. 2012), that is, a hyperfunctional adaptation to vocal demand (Remacle et al. 2018). Some previous studies have shown that higher $f_{o}$ following teachers' voice use may be accompanied by an increase in self-reported vocal symptoms (Rantala and Vilkman 1999; Remacle et al. 2012), while others found no association between ambulatory measures during daily lessons and self-reported voice complaints (Cantor Cutiva et al. 2017).

Logically enough, age and teaching experience are strongly correlated. Although earlier studies have described longer durations of phonation in teachers aged over 50 years (Astolfi et al. 2015) and teachers with more than 21 years of teaching experience (Puglisi et al. 2017), we did not observe any effect of age or teaching experience on vocal acoustic parameters. Moreover, the ambulatory measures of fundamental frequency and intensity do not confirm the age-related changes described in the literature (Bottalico and Astolfi 2012; Nishio and Niimi 2008). The absence of a link between the participants' age and experience, on the one hand, and their ambulatory acoustic parameters, on the other hand, is difficult to explain. Further in situ studies are needed to unravel this point.

Regarding inflammatory influences, three men and seven women in this study consumed tobacco. Although cigarette smoking has been associated with lower VHI scores and lower speaking $f_{o}$ (Ayoub et al. 2019), we did not find such effects. Indeed, there is no correlation between tobacco consumption and VHI score. In addition, tobacco consumption has no significant effect on any of the vocal parameters, including fundamental frequency. Note that we did not collect information about the number of years of tobacco consumption. Finally, gastro-esophageal problems, which five women and eight men suffered from, did not influence the examined vocal acoustic parameters.

\subsection{Limitations and prospects for future research}

In communication situations encountered by professional voice users, vocal demand responses are multifactorial. Based on epidemiological models such as Haddon's (1980), voice injuries are known to result from interactions between the vocalist (host), the physical energy transferred to his/her vocal folds (agent), and the environment. In this study, we investigated the impact of ten influencing factors on schoolteachers' vocal acoustic parameters. Additional factors pertaining to the vocalist should be studied, such as medication use, alcohol consumption, asthma, allergies, sedentarity, hormones, women's menstrual cycle, menopause, stress, and personality This is a post-peer-review, pre-copyedit version of an article published in International Archives of Occupational and

Environmental Health. The final authenticated version is available online at: http://dx.doi.org/10.1007/s00420-021-01681-3 
Factors predicting teachers' vocal acoustic parameters

traits. Analysis of daily and weekly voice changes in relation to influencing factors may help to detect different patterns of responses. A next step would be to study the ambulatory voice parameters in light of several environmental factors together, such as background noise level, reverberation, room size, temperature, and humidity. Controlling certain environmental factors may help to mitigate the vocal risk among teachers. Future studies combining environmental and individual factors are necessary to acquire a more complete understanding of teachers' vocal behavior and better identify vulnerable individuals and risky situations.

Regarding the agent of injury, excessive mechanical load related to vibration is potentially damaging to vocal fold tissue, but its effect on laryngeal muscles is less straightforward. For instance, Titze (2017) argued that the morphology of the vocal folds appears to be optimized for communication at higher $f_{\mathrm{o}}$ and SPL and with more voiced segments than are found in actual human speech patterns. Contemporary voice use tends to produce a contracture of the laryngeal muscles and some vocal behaviors counterbalance this contracture, such as raising one's voice to call, shout, or sing (Titze 2017). Future research should unravel the exact impact of mechanical load on vocal fold tissue versus muscle, taking into account the great inter-individual variability in vocal demand response.

\section{Conclusions}

As is unanimously recognized in the field of occupational voice, it is crucial to identify subgroups with higher risks of voice problems. Long-term monitoring of voice behavior was made possible thanks to the use of dosimetry. The main contribution of this work was to consider a large set of influencing factors together to predict acoustic measures of 87 teachers' voices tracked for a total of 431 days.

Our results show that higher ambulatory measures of $f_{o}$ are statistically predicted by being a woman, teaching a lower grade and having a higher VHI score. On the one hand, the higher-pitched voices of kindergarten and elementary female teachers may be due to the Lombard effect, the convergence effect, the characteristics of child-directed speech, or the cognitive and/or emotional load related to occupational stress. On the other hand, lowering the pitch may be a strategy secondary and university teachers use to assert their authority. In addition, lower ambulatory measures of $f_{o}$ are statistically predicted by engaging in a vocally demanding nonoccupational activity, which is likely to increase mechanical load.

Considering the high prevalence of voice problems among teachers, researchers agree that primary

prevention and early detection are key. Given their cost, these actions should be made available primarily to This is a post-peer-review, pre-copyedit version of an article published in International Archives of Occupational and

Environmental Health. The final authenticated version is available online at: http://dx.doi.org/10.1007/s00420-021-01681-3 
Factors predicting teachers' vocal acoustic parameters

individuals at risk of developing vocal fold tissue damage due to mechanical load, namely females, and specifically those teaching at the kindergarten and elementary levels, who have substantially higher $f_{o}$ than those teaching higher grades. In addition, self-assessment questionnaires such as the VHI could also help to detect individuals with potentially harmful $f_{o}$ voice patterns.

\section{Declarations}

Conflicts of interest: There are no conflicts of interest.

Funding statement: Angélique Remacle was funded by the Fund for Scientific Research - F.R.S.-FNRS (Brussels, Belgium).

Acknowledgments: We express our gratitude to the teachers and school administrators who participated in this research. We would also like to thank the speech therapy students who helped with the data collection: Anaëlle Alcoulombre, Sarah Chesser, Marine De Brossard, Laetitia De Chambourcy, Pauline Georges, Lucie Hubinon, Armelle Laureys, Mathilde Paboeuf, Raphä̈lle Rousseaux, and Marie Simon.

Availability of data and material: Data are available upon reasonable request.

Author contributions: AR: study conceptualization and design, methodology, data acquisition and analysis, writing - original draft preparation and review. NL: statistical analysis. 
Factors predicting teachers' vocal acoustic parameters

\section{References}

Agai-Demjaha T, Karadzinska Bislimovska J, Mijakoski D (2015) Level of work related stress among teachers in elementary schools. Open Access Maced J Med Sci 3(3):484-488. http://dx.doi.org/10.3889/oamjms.2015.076

Astolfi A, Carullo A, Pavese L, Puglisi GE (2015) Duration of voicing and silence periods of continuous speech in different acoustic environments. J Acoust Soc Am 137(2):565-579. https://doi.org/10.1121/1.4906259

Ayoub MR, Larrouy-Maestri P, Morsomme D (2019) The effect of smoking on the fundamental frequency of the speaking voice. J Voice 33(5):802.e11-802.e16. https://doi.org/10.1016/j.jvoice.2018.04.001

Bottalico P, Astolfi A (2012) Investigations into vocal doses and parameters pertaining to primary school teachers in classrooms. J Acoust Soc Am 131(4):2817-2827. https://doi.org/10.1121/1.3689549

Bottalico P, Graetzer S, Astolfi A, Hunter EJ (2017) Silence and voicing accumulations in Italian primary school teachers with and without voice disorders. J Voice 31(2):260.e11-260.e20. https://doi.org/10.1016/j.jvoice.2016.05.009

Bottalico P, Passione II, Astolfi A, Carullo A, Hunter EJ (2018) Accuracy of the quantities measured by four vocal dosimeters and its uncertainty. J Acoust Soc Am 143(3): 1591-1602. https://asa.scitation.org/toc/jas/143/3

Calosso G, Puglisi GE, Astolfi A, Castellana A, Carullo A, Pellerey F (2017) A one-school year longitudinal study of secondary school teachers' voice parameters and the influence of classroom acoustics. J Acoust Soc Am 142(2):1055-1066. https://doi.org/10.1121/1.4998707

Cantor Cutiva LC, Puglisi GE, Astolfi A, Carullo A (2017) Four-day follow-up study on the self-reported voice condition and noise condition of teachers: Relationship between vocal parameters and classroom acoustics. J Voice 31(1):120.e121-120.e128. https://doi.org/10.1016/j.jvoice.2016.02.017

Chui JCH, Ma EPM (2019) The impact of dysphonic voices on children's comprehension of spoken language. J Voice 33(5):801.e7-801.e16. https://doi.org/10.1016/j.jvoice.2018.03.004

de Jong FICRS (2010) An introduction to the teacher's voice in a biopsychosocial perspective. Folia Phoniatr Logop 62(1-2):5-8. https://doi.org/10.1159/000239058

Epstein R, Remacle A, Morsomme D (2011) From reactive intervention to proactive prevention: The evolution of occupational dysphonia. Perspect Voice Voice Disorders 21(2):48-55. https://doi.org/10.1044/vvd21.2.48

Haddon W (1980) Advances in the epidemiology of injuries as a basis for public policy. Public Health Rep This is a post-peer-review, pre-copyedit version of an article published in International Archives of Occupational and Environmental Health. The final authenticated version is available online at: http://dx.doi.org/10.1007/s00420-021-01681-3 
Factors predicting teachers' vocal acoustic parameters

95(5):411-421.

Hazlett DE, Duffy OM, Moorhead SA (2011) Review of the impact of voice training on the vocal quality of professional voice users: Implications for vocal health and recommendations for further research. J Voice 25(2):181-191. https://doi.org/10.1016/j.jvoice.2009.08.005

Hunter EJ, Cantor-Cutiva LC, van Leer E et al (2020) Toward a consensus description of vocal effort, vocal load, vocal loading, and vocal fatigue. J Speech Lang Hear Res 63:509-532. https://doi.org/10.1044/2019_JSLHR-19-00057

Hunter EJ, Tanner K, Smith ME (2011) Gender differences affecting vocal health of women in vocally demanding careers. Logop Phoniatr Vocol 36(3):128-136. https://doi.org/10.3109/14015439.2011.587447

Hunter, EJ, Titze IR (2010) Variations in intensity, fundamental frequency, and voicing for teachers in occupational versus nonoccupational settings. J Speech Lang Hear Res 53(4):862-875. https://doi.org/10.1044/10924388(2009/09-0040)

KayPENTAX. (2009) Ambulatory Phonation Monitor (APM) Model 3200. Software instruction manual, issue B. Lincoln Park, NJ: PENTAX Medical Company.

Kelleher JE, Siegmund T, Chan RW (2014) Collagen microstructure in the vocal ligament: Initial results on the potential effects of smoking. Laryngoscope 124:361-367. https://doi.org/10.1002/lary.24626

Kooijman PGC, de Jong FICRS, Thomas G, Huinck W, Donders R, Graamans K, Schutte HK (2006) Risk factors for voice problems in teachers. Folia Phoniatr Logop 58(3):159-174. https://doi.org/10.1159/000091730

Kooijman PGC, Thomas G, Graamans K, de Jong FICRS (2007) Psychosocial impact of the teacher's voice throughout the career. J Voice 21(3):316-324. https://doi.org/10.1016/j.jvoice.2005.12.007

Lechien JR, Finck C, Costa de Araujo P et al (2017) Voice outcomes of laryngopharyngeal reflux treatment: A systematic review of 1483 patients. Eur Arch Oto-Rhino-L 274(1):1-23. https://doi.org/10.1007/s00405016-3984-7

Lee DK (2016) Alternatives to P value: Confidence interval and effect size. Korean J Anesthesiol 69(6): 555-562. https://doi.org/10.4097/kjae.2016.69.6.555

Lyberg-Åhlander V, Haake M, Brännström J, Schötz S, Sahlén B (2015) Does the speaker's voice quality influence children's performance on a language comprehension test? Int J Speech-Lang Pathol 17(1):63-73. https://doi.org/10.3109/17549507.2014.898098

This is a post-peer-review, pre-copyedit version of an article published in International Archives of Occupational and Environmental Health. The final authenticated version is available online at: http://dx.doi.org/10.1007/s00420-021-01681-3 
Factors predicting teachers' vocal acoustic parameters

Malik JL, Mueller RO, Meinke DL (1991) The effects of teaching experience and grade level taught on teacher stress: A LISREL analysis. Teach Teach Educ 7(1):57-62.

Manfredi C, Dejonckere PH (2016) Voice dosimetry and monitoring, with emphasis on professional voice diseases: Critical review and framework for future research. Logop Phoniatr Vocol 41(2):49-65. https://doi.org/10.3109/14015439.2014.970228

Martins RHG, Pereira ERBN, Hidalgo CB, Tavares ELM (2014) Voice disorders in teachers: A review. J Voice 28(6):716-724. https://doi.org/10.1016/j.jvoice.2014.02.008

Masuda T, Ikeda Y, Manako H, Komiyama S (1993) Analysis of vocal abuse: Fluctuations in phonation time and intensity in 4 groups of speakers. Acta Oto-Laryngol 113:547-552.

Morrow SL, Connor NP (2011) Comparison of voice-use profiles between elementary classroom and music teachers. J Voice 25(3):367-372. https://doi.org/10.1016/j.jvoice.2009.11.006

Munier C, Kinsella R (2008) The prevalence and impact of voice problems in primary school teachers. Occup Med 58:74-76. https://doi.org/10.1093/occmed/kqm104

Nishio M, Niimi S (2008) Changes in speaking fundamental frequency characteristics with aging. Folia Phoniatr Logop 60(3):120-127. https://doi.org/10.1159/000118510

Nusseck M, Richter B, Spahn C, Echternach M (2018) Analysing the vocal behaviour of teachers during classroom teaching using a portable voice accumulator. Logop Phoniatr Vocol 43(1):1-10. https://doi.org/10.1080/14015439.2017.1295104

Picard M, Bradley JS (2001) Revisiting speech interference in classrooms: Revisando la interferencia en el habla dentro del salón de clases. Int J Audiol 40(5):221-244. https://doi.org/10.3109/00206090109073117

Pirilä S, Pirilä P, Ansamaa T, Yliherva A, Sonning S, Rantala L (2017) Relationship between activity noise, voice parameters, and voice symptoms among female teachers. Folia Phoniatr Logop 69(3):94-102. https://doi.org/10.1159/000484204

Preciado J A, García Tapia R, Infante JC (1998) [Prevalence of voice disorders among educational professionals. Factors contributing to their appearance or their persistence]. Acta Otorrinolaringolo Esp 49(2):137-142.

Puglisi G., Astolfi A, Cantor Cutiva LC, Carullo A (2017) Four-day-follow-up study on the voice monitoring of primary school teachers: Relationships with conversational task and classroom acoustics. J Acoust Soc Am 141(1):441-452. https://doi.org/10.1121/1.4973805

This is a post-peer-review, pre-copyedit version of an article published in International Archives of Occupational and Environmental Health. The final authenticated version is available online at: http://dx.doi.org/10.1007/s00420-021-01681-3 
Factors predicting teachers' vocal acoustic parameters

Rantala L, Vilkman E (1999) Relationship between subjective voice complaints and acoustic parameters in female teachers' voices. J Voice 13(4):484-495. https://doi.org/10.1016/S0892-1997(99)80004-6

Remacle A, Garnier M, Gerber S, David C, Petillon C (2018) Vocal change patterns during a teaching day: Inter- and intra-subject variability. J Voice 32(1):57-63. https://doi.org/10.1016/j.jvoice.2017.03.008

Remacle A, Morsomme D, Berrué E, Finck C (2012) Vocal impact of a prolonged reading task in dysphonic versus normophonic female teachers. J Voice 26(6):820.e1-820.e13. https://doi.org/10.1016/j.jvoice.2012.06.002

Remacle A, Morsomme D, Finck C (2014) Comparison of vocal loading parameters in kindergarten and elementary school teachers. J Speech Lang Hear Res 57(2):406-415. https://doi.org/10.1044/2013 JSLHR-S-12-0351

Roy N, Merrill RM, Thibeault S, Parsa RA, Gray SD, Smith EM (2004) Prevalence of voice disorders in teachers and the general population. J Speech Lang Hear Res 47(2):281-293. https://doi.org/10.1044/1092$4388(2004 / 023)$

Runyan CW (2003) Introduction: Back to the future: Revisiting Haddon's conceptualization of injury epidemiology and prevention. Epidemiol Rev 25(1):60-64. https://doi.org/10.1093/epirev/mxg005

Saint-Georges C, Chetouani M, Cassel R et al (2013) Motherese in interaction: At the cross-road of emotion and cognition? (A systematic review). PLoS ONE 8(10):e78103. https://doi.org/10.1371/journal.pone.0078103

Sala E, Airo E, Olkinuora P et al (2002) Vocal loading among day care center teachers. Logop Phoniatr Vocol 27(1):21-28. https://doi.org/10.1080/140154302760146943

Sato M, Grabski K, Garnier M, Granjon L, Schwartz J-L, Nguyen N (2013) Converging toward a common speech code: Imitative and perceptuo-motor recalibration processes in speech production. Front Psychol 4:422. https://doi.org/10.3389/fpsyg.2013.00422

Schiller IS, Morsomme D, Kob M, Remacle A (2020) Noise and a speaker's impaired voice quality disrupt spoken language processing in school-aged children: Evidence from performance and response time measures. J Speech Lang Hear Res 63(7):2115-2131. https://doi.org/10.1044/2020_JSLHR-19-00348

Schiller IS, Morsomme D, Remacle A (2018) Voice use among music theory teachers: A voice dosimetry and selfassessment study. J Voice 32(5):578-584. https://doi.org/10.1016/j.jvoice.2017.06.020

Smith AG, Sandage MJ, Pascoe DD, Plexico LW, Lima IR, Cao G (2017) Elementary school teachers' vocal dose: Muscle bioenergetics and training implications. J Speech Lang Hear Res 60(7):1831-1842. https://doi.org/10.1044/2016_JSLHR-S-16-0193

This is a post-peer-review, pre-copyedit version of an article published in International Archives of Occupational and Environmental Health. The final authenticated version is available online at: http://dx.doi.org/10.1007/s00420-021-01681-3 
Factors predicting teachers' vocal acoustic parameters

Szabo Portela A, Granqvist S, Ternström S, Södersten M (2018) Vocal behavior in environmental noise: Comparisons between work and leisure conditions in women with work-related voice disorders and matched controls. J Voice 32:126.e23-126.e38.

Thibeault S (2004) Occupational risk factors associated with voice disorders among teachers. Ann Epidemiol 14(10):786-792. https://doi.org/10.1016/j.annepidem.2004.03.004

Titze IR (2000) Principles of voice production, 2nd ed. National Center for Voice and Speech, Iowa City.

Titze IR (2017) Human speech: A restricted use of the mammalian larynx. J Voice 31(2):135-141. http://dx.doi.org/10.1016/j.jvoice.2016.06.003

Titze IR, Hunter EJ (2015) Comparison of vocal vibration-dose measures for potential-damage risk criteria. J Speech Lang Hear Res 58(5):1425-1439. https://doi.org/10.1044/2015_JSLHR-S-13-0128

Van Houtte E, Claeys S, Wuyts F, Van Lierde K (2011) The impact of voice disorders among teachers: Vocal complaints, treatment-seeking behavior, knowledge of vocal care, and voice-related absenteeism. J Voice 25(5):570-575. https://doi.org/10.1016/j.jvoice.2010.04.008

Van Houtte E, Van Lierde K, D'Haeseleer E, Claeys S (2010) The prevalence of laryngeal pathology in a treatmentseeking population with dysphonia. Laryngoscope 120(2):306-312. https://doi.org/10.1002/lary.20696

Van Puyvelde M, Neyt X, McGlone F, Pattyn N (2018) Voice stress analysis: A new framework for voice and effort in human performance. Front Psychol 9:1994. https://doi.org/10.3389/fpsyg.2018.01994

Van Stan JH, Mehta DD, Zeitels SM, Burns JA, Barbu AM, Hillman RE (2015) Average ambulatory measures of sound pressure level, fundamental frequency, and vocal dose do not differ between adult females with phonotraumatic lesions and matched control subjects. Ann Otol Rhinol Laryngol 124(11):864-874. https://doi.org/10.1177/0003489415589363

Vertanen-Greis H, Löyttyniemi E, Uitti J (2018) Voice disorders are associated with stress among teachers: A crosssectional study in Finland. J Voice 34(3):488.e1-488.e8. https://doi.org/10.1016/j.jvoice.2018.08.021

Vilkman E (2004) Occupational safety and health aspects of voice and speech professions. Folia Phoniatr Logop 56(4):220-253. https://doi.org/10.1159/000078344

Woisard V, Bodin S, Puech M (2004) [The Voice Handicap Index: Impact of the translation in French on the validation]. Rev Laryngol Otol Rhinol 125(5):307-312. http://www.revuelaryngologie.com/detail_print.lasso?id=7ebf8a6543c3cc73

This is a post-peer-review, pre-copyedit version of an article published in International Archives of Occupational and Environmental Health. The final authenticated version is available online at: http://dx.doi.org/10.1007/s00420-021-01681-3 
Factors predicting teachers' vocal acoustic parameters

Yiu EM-L., Yip PPS (2016) Effect of noise on vocal loudness and pitch in natural environments: An accelerometer (Ambulatory Phonation $\quad$ Monitor) study. J $\quad$ Voice https://doi.org/10.1016/j.jvoice.2015.05.016 
Factors predicting teachers' vocal acoustic parameters

Table 1. Overview of the influencing factors according to teachers' gender

\begin{tabular}{|c|c|c|c|c|c|c|}
\hline & \multicolumn{2}{|c|}{$\begin{array}{l}\text { Female } \\
(\mathrm{n}=66)\end{array}$} & \multicolumn{2}{|c|}{$\begin{array}{l}\text { Male } \\
(\mathrm{n}=21)\end{array}$} & \multicolumn{2}{|c|}{$\begin{array}{l}\text { All } \\
(\mathrm{n}=87)\end{array}$} \\
\hline & n & $\%$ & n & $\%$ & n & $\%$ \\
\hline \multicolumn{7}{|l|}{ Teaching level } \\
\hline Kindergarten & 21 & 24.1 & 0 & 0.0 & 21 & 24.1 \\
\hline Elementary & 20 & 23.0 & 0 & 0.0 & 20 & 23.0 \\
\hline Secondary & 20 & 23.0 & 15 & 17.2 & 35 & 40.2 \\
\hline University & 5 & 5.7 & 6 & 6.9 & 11 & 12.6 \\
\hline \multicolumn{7}{|l|}{ Tobacco } \\
\hline No & 59 & 67.8 & 18 & 20.7 & 77 & 88.5 \\
\hline Yes & 7 & 8.0 & 3 & 3.4 & 10 & 11.5 \\
\hline \multicolumn{7}{|l|}{ Gastro-esophageal problems } \\
\hline No & 56 & 64.4 & 16 & 18.4 & 72 & 82.8 \\
\hline Yes & 10 & 11.5 & 5 & 5.7 & 15 & 17.2 \\
\hline \multicolumn{7}{|l|}{ Nonoccupational voice activity } \\
\hline No & 51 & 58.6 & 16 & 18.4 & 67 & 77.0 \\
\hline Yes & 15 & 17.2 & 5 & 5.7 & 20 & 23.0 \\
\hline \multicolumn{7}{|l|}{ Voice education } \\
\hline No & 50 & 57.5 & 15 & 17.2 & 65 & 74.7 \\
\hline Yes & 16 & 18.4 & 6 & 6.9 & 22 & 25.3 \\
\hline \multicolumn{7}{|l|}{ Past voice problems } \\
\hline No & 44 & 50.6 & 14 & 16.1 & 58 & 66.7 \\
\hline \multirow[t]{2}{*}{ Yes } & 22 & 25.3 & 7 & 8.0 & 29 & 33.3 \\
\hline & mean & SD & mean & SD & mean & SD \\
\hline Age (years) & 39.0 & 9.3 & 43 & 9.6 & 40 & 9.5 \\
\hline \multicolumn{7}{|l|}{ Age per teaching level (years) } \\
\hline Kindergarten & 39.3 & 7.9 & - & - & 39.3 & 7.9 \\
\hline Elementary & 39.2 & 9.1 & - & - & 39.2 & 9.1 \\
\hline Secondary & 37.6 & 10.6 & 40.7 & 9.6 & 38.9 & 10.2 \\
\hline University & 42.6 & 11.6 & 48.8 & 7.4 & 46.0 & 9.6 \\
\hline Teaching experience (years) & 14.7 & 8.6 & 16.6 & 8.0 & 15.2 & 8.5 \\
\hline VHI score & 11.2 & 10.5 & 12.7 & 9.1 & 11.6 & 10.2 \\
\hline
\end{tabular}

This is a post-peer-review, pre-copyedit version of an article published in International Archives of Occupational and Environmental Health. The final authenticated version is available online at: http://dx.doi.org/10.1007/s00420-021-01681-3 
Table 2. Relationships between the influencing factors

\begin{tabular}{lllll}
\hline Variables & Test & Test value & df & $\begin{array}{l}\text { P- } \\
\text { value }\end{array}$ \\
\hline Tobacco*Gastro-esophageal problems & Pearson chi-square & $\mathrm{r}=.06$ & 1 & .806 \\
Gender*Teaching level & Pearson chi-square & $\mathrm{r}=25.29$ & 3 & $<.001$ \\
$\begin{array}{l}\text { Voice problems*Voice education } \\
\text { Voice education*Nonoccupational voice }\end{array}$ & Pearson chi-square & $\mathrm{r}=.76$ & 1 & .383 \\
$\begin{array}{l}\text { activity } \\
\text { Nonoccupational voice }\end{array}$ & & $\mathrm{r}=.30$ & 1 & .581 \\
problems & Pearson chi-square & $\mathrm{r}=.51$ & 1 & .471 \\
$\begin{array}{l}\text { Past voice problems*VHI score } \\
\text { Gender*VHI score }\end{array}$ & One-way ANOVA & $\mathrm{F}=9.43$ & 1 & .003 \\
Voice education*VHI score & One-way ANOVA & $\mathrm{F}=0.31$ & 1 & .579 \\
Age*Teaching experience & One way ANOVA & $\mathrm{F}=.208$ & 1 & .649 \\
Age*VHI score & Pearson correlation & $\mathrm{r}=.85$ & 85 & $<.001$ \\
Teaching experience*VHI score & Pearson correlation & $\mathrm{r}=-.22$ & 85 & .038 \\
\hline & Pearson correlation & $\mathrm{r}=-.21$ & 85 & .043 \\
\hline
\end{tabular}


Factors predicting teachers' vocal acoustic parameters

Table 3. Results of the general linear mixed models for voicing time, SPL, and $f_{p}$

\begin{tabular}{|c|c|c|c|c|c|c|}
\hline & & & & & & $95 \%$ confidence interval \\
\hline Voicing time $(\%)$ & Estimate & Standard error & df & t-value & $\mathrm{p}$-value & (lower bound-upper bound) \\
\hline Intercept & 9.05 & 2.1 & 1,74 & 4.35 & $<.001$ & $4.9-13.2$ \\
\hline Gender $=$ female & 0.2 & 0.6 & 1,74 & .38 & .706 & $-1.0-1.5$ \\
\hline Age & 0.04 & 0.1 & 1,74 & .82 & .416 & $-0.06-0.1$ \\
\hline Teaching experience & -0.02 & 0.1 & 1,74 & -.41 & .682 & $-0.1-0.1$ \\
\hline Teaching level $*=1$ & 0.3 & 1.0 & 3,74 & .33 & .739 & $-1.6-2.2$ \\
\hline Teaching level $*=2$ & 0.8 & 0.9 & 3,74 & .92 & .361 & $-1.0-2.6$ \\
\hline Teaching level $*=3$ & -0.1 & 0.8 & 3,74 & -.07 & .945 & $-1.6-1.5$ \\
\hline Tobacco $=$ no & -0.1 & 0.7 & 1,74 & -.17 & .868 & $-1.6-1.3$ \\
\hline Gastro-esophageal problems $=$ no & 0.6 & 0.7 & 1,74 & .95 & .343 & $-0.7-2.0$ \\
\hline Nonoccupational voice activity $=$ no & -1.0 & 0.6 & 1,74 & -1.70 & .093 & $-2.1-0.2$ \\
\hline Voice education $=$ no & -0.8 & 0.5 & 1,74 & -1.49 & .140 & $-1.9-0.3$ \\
\hline Past voice problems $=$ no & -0.6 & 0.5 & 1,74 & -1.16 & .248 & $-1.6-0.4$ \\
\hline VHI score & -0.03 & 0.02 & 1,74 & -1.04 & .301 & $-0.1-0.02$ \\
\hline Voice SPL (dB) & Estimate & Standard error & df & t-value & p-value & $95 \%$ confidence interval \\
\hline Intercept & 69.3 & 6.3 & 1,74 & 11.03 & $<.001$ & $56.8-81.8$ \\
\hline Gender $=$ female & -0.1 & 1.9 & 1,74 & -.04 & .967 & $-3.9-3.8$ \\
\hline Age & 0.1 & 0.1 & 1,74 & .37 & .712 & $-0.2-0.4$ \\
\hline Teaching experience & -0.01 & 0.2 & 1,74 & -.08 & .934 & $-0.4-0.3$ \\
\hline Teaching level $*=1$ & 5.0 & 2.9 & 3,74 & 1.72 & .089 & $-0.8-10.7$ \\
\hline Teaching level $*=2$ & 3.9 & 2.7 & 3,74 & 1.41 & .163 & $-1.6-9.3$ \\
\hline Teaching level $*=3$ & 4.3 & 2.4 & 3,74 & 1.80 & .076 & $-0.5-9.0$ \\
\hline Tobacco $=$ no & 0.6 & 2.2 & 1,74 & .28 & .778 & $-3.8-5.0$ \\
\hline Gastro-esophageal problems $=$ no & -1.2 & 2.0 & 1,74 & -.59 & .556 & $-5.2-2.8$ \\
\hline Nonoccupational voice activity $=$ no & 0.4 & 1.7 & 1,74 & .22 & .827 & $-3.0-3.7$ \\
\hline Voice education $=$ no & -0.3 & 1.6 & 1,74 & -.20 & .845 & $-3.6-2.9$ \\
\hline Past voice problems $=$ no & 0.8 & 1.6 & 1,74 & .50 & .621 & $-2.4-3.9$ \\
\hline VHI score & -0.02 & 0.1 & 1,74 & -.24 & .806 & $-0.2-0.1$ \\
\hline Voice $f_{o}(\mathrm{~Hz})$ & Estimate & Standard error & df & t-value & p-value & $95 \%$ confidence interval \\
\hline Intercept & 126.6 & 19.4 & 1,74 & 6.51 & $<.001$ & $87.9-165.3$ \\
\hline Gender $=$ female & 68.5 & 5.9 & 1,74 & 11.49 & $<.001$ & $56.7-80.4$ \\
\hline Age & -0.5 & 0.5 & 1,74 & -.95 & .343 & $-1.4-0.5$ \\
\hline Teaching experience & 0.03 & 0.5 & 1,74 & .06 & .952 & $-1.0-1.1$ \\
\hline Teaching level $*=1$ & 52.9 & 8.9 & 3,74 & 5.91 & $<.001$ & $35.1-70.7$ \\
\hline Teaching level $*=2$ & 39.9 & 8.5 & 3,74 & 4.69 & $<.001$ & $23.0-56.9$ \\
\hline Teaching level $*=3$ & 25.4 & 7.4 & 3,74 & 3.44 & .001 & $10.7-40.1$ \\
\hline Tobacco $=$ no & 11.7 & 6.8 & 1,74 & 1.72 & .089 & $-1.8-25.3$ \\
\hline Gastro-esophageal problems $=$ no & 4.8 & 6.3 & 1,74 & .77 & .444 & $-7.7-17.4$ \\
\hline Nonoccupational voice activity $=$ no & 10.9 & 5.2 & 1,74 & 2.08 & .041 & $0.47-21.3$ \\
\hline Voice education $=$ no & -5.7 & 5.1 & 1,74 & -1.13 & .263 & $-15.2-4.4$ \\
\hline Past voice problems $=$ no & -3.1 & 4.9 & 1,74 & -.63 & .528 & $-12.8-6.6$ \\
\hline VHI score & 0.7 & 0.2 & 1,74 & 2.99 & .004 & $0.2-1.2$ \\
\hline
\end{tabular}

Note. For teaching level, 1 = kindergarten, 2 = elementary, $3=$ secondary. ${ }^{*}$ The reference level for comparisons is university.

This is a post-peer-review, pre-copyedit version of an article published in International Archives of Occupational and Environmental Health. The final authenticated version is available online at: http://dx.doi.org/10.1007/s00420-021-01681-3 
Factors predicting teachers' vocal acoustic parameters

Table 4. Estimated marginal means for $f_{o}(\mathrm{~Hz})$ according to gender

\begin{tabular}{lllll}
\hline & Females & & Males & \\
\cline { 2 - 5 } & Mean & Standard error & Mean & Standard error \\
\hline Gender $^{\mathrm{a}}$ & 224.5 & 4.6 & 155.9 & 6.3 \\
Nonoccupational voice activity $^{\mathrm{b}}$ & & & & \\
$\quad$ No & 229.3 & 5.2 & 144.0 & 7.1 \\
$\quad$ Yes & 219.2 & 7.05 & 140.6 & 10.2 \\
Teaching level $^{\mathrm{b}}$ & & & \\
$\quad$ Kindergarten $^{\text {Elementary }}$ & 250.2 & 7.22 & - & - \\
$\quad$ Secondary & 236.9 & 6.6 & - & - \\
$\quad$ University & 225.3 & 6.4 & 138.1 & 7.4 \\
\hline
\end{tabular}

Note. ${ }^{a}$ To estimate the $f_{o}$ values, the continuous variables of the overall $f_{o}$ model $(\mathrm{n}=87)$ were set at their mean values: age $=40$, teaching experience $=15$, VHI score $=11.6$.

${ }^{\mathrm{b}}$ To estimate the female $f_{o}$ values, the continuous variables of the $f_{o}$ model for females $(\mathrm{n}=66)$ were set at their mean values: age $=39$, teaching experience $=14$, VHI score $=11$.

To estimate the male $f_{o}$ values, the continuous variables of the $f_{o}$ model for males $(\mathrm{n}=21)$ were set at their mean values: age $=43$, teaching experience $=17, \mathrm{VHI}$ score $=12$. 
Table 5. Pairwise comparisons of teaching levels based on estimated marginal means for $f_{o}(\mathrm{~Hz})$ in the overall sample (males and females) and in females only

\begin{tabular}{|c|c|c|c|c|c|}
\hline \multirow[b]{2}{*}{ Teaching levels compared } & \multirow[b]{2}{*}{ Averaged mean difference } & \multirow[b]{2}{*}{ Standard error } & \multirow[b]{2}{*}{$\mathbf{p}^{*}$} & \multicolumn{2}{|c|}{$95 \%$ confidence interval for difference } \\
\hline & & & & Lower bound & Upper bound \\
\hline \multicolumn{6}{|l|}{ Males and females $(n=87)$} \\
\hline Kindergarten vs. Elementary & 13.0 & 6.5 & .303 & -4.7 & 30.7 \\
\hline Kindergarten vs. Secondary & 27.5 & 6.3 & $<.001$ & 10.4 & 44.7 \\
\hline Kindergarten vs. University & 52.9 & 8.9 & $<.001$ & 28.7 & 77.2 \\
\hline Elementary vs. Secondary & 14.5 & 6.4 & .148 & -2.6 & 31.7 \\
\hline Elementary vs. University & 39.9 & 8.5 & $<.001$ & 16.9 & 63.0 \\
\hline Secondary vs. University & 25.4 & 7.4 & .006 & 5.4 & 45.4 \\
\hline \multicolumn{6}{|l|}{ Females $(n=66)$} \\
\hline Kindergarten vs. Elementary & 13.2 & 6.7 & .330 & -5.2 & 31.7 \\
\hline Kindergarten vs. Secondary & 24.9 & 6.8 & .003 & 6.4 & 43.4 \\
\hline Kindergarten vs. University & 65.7 & 10.6 & $<.001$ & 36.7 & 94.6 \\
\hline Elementary vs. Secondary & 11.7 & 6.7 & .515 & -6.6 & 30.0 \\
\hline Elementary vs. University & 52.4 & 10.3 & $<.001$ & 24.2 & 80.6 \\
\hline Secondary vs. University & 40.7 & 10.3 & .001 & 12.6 & 68.8 \\
\hline
\end{tabular}

Note. $*$ The mean difference is significant at the .05 level. Adjustment for multiple comparisons: sequential Bonferroni procedure. 
Supplemental material. Overview of the participants' individual characteristics and vocal acoustic parameters. Each teacher wore the Ambulatory Phonation Monitor for five full days of normal activities in a typical workweek.

\begin{tabular}{|c|c|c|c|c|c|c|c|c|c|c|c|c|c|c|c|c|c|c|}
\hline \multirow{2}{*}{\multicolumn{12}{|c|}{ Individual characteristics }} & \multicolumn{7}{|c|}{ Vocal acoustic parameters } \\
\hline & & & & & & & & & & & & & & & & & & \\
\hline \multirow[b]{2}{*}{ 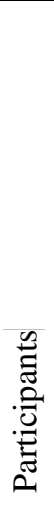 } & \multirow{2}{*}{\multicolumn{3}{|c|}{ 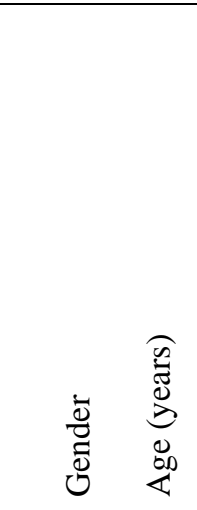 }} & \multirow[b]{2}{*}{ 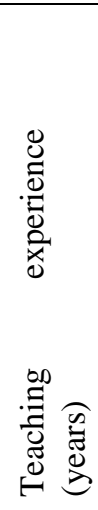 } & \multirow[b]{2}{*}{ 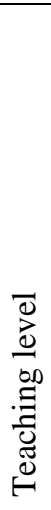 } & \multirow[b]{2}{*}{$\begin{array}{l}0 \\
0 \\
0 \\
0 \\
0 \\
0 \\
0 \\
0 \\
0\end{array}$} & \multirow[b]{2}{*}{ 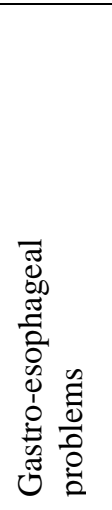 } & \multirow[b]{2}{*}{ 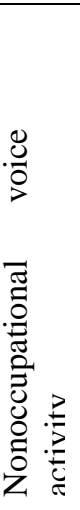 } & \multirow[b]{2}{*}{$\begin{array}{l} \\
0 \\
.0 \\
0 \\
0 \\
0 \\
0 \\
0 \\
0 \\
0 \\
0\end{array}$} & \multirow[b]{2}{*}{ 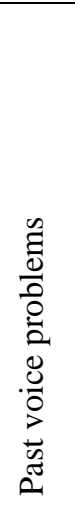 } & \multirow[b]{2}{*}{ 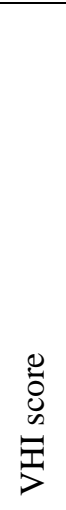 } & \multicolumn{4}{|c|}{ Weekly measures } & \multicolumn{3}{|c|}{ Pearson correlations (r) } \\
\hline & & & & & & & & & & & & 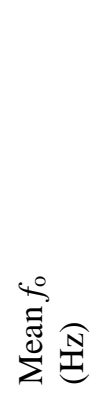 & 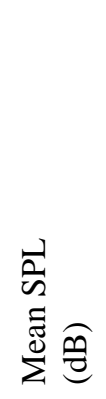 & 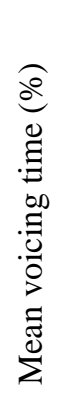 & 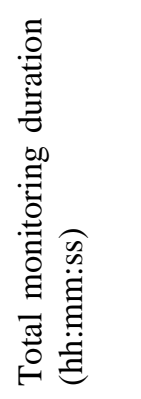 & \begin{tabular}{l}
$\overrightarrow{2}$ \\
\multirow{2}{*}{} \\
$*$ \\
$* 0$
\end{tabular} & 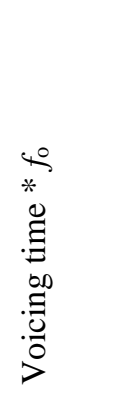 & 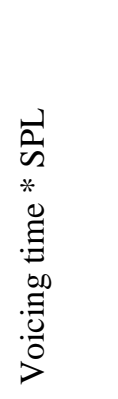 \\
\hline 1 & 0 & & 39 & 15 & 2 & no & yes & yes & yes & no & 5 & 243.6 & 76.3 & 13.6 & $46: 14: 56$ & $.492 * *$ & $-.069 * *$ & $-.113 * *$ \\
\hline 2 & 0 & & 50 & 25 & 2 & no & no & no & yes & yes & 6 & 289.2 & 80.4 & 22.1 & $23: 14: 21$ & $.585 * *$ & $.093 * *$ & $.052 * *$ \\
\hline 3 & 0 & & 36 & 11 & 1 & no & no & no & no & no & 8 & 277.5 & 80.9 & 15.1 & $54: 15: 38$ & $.514^{* *}$ & $-.114 * *$ & $-.148 * *$ \\
\hline 4 & 1 & & 32 & 11 & 3 & no & no & yes & no & no & 15 & 159.8 & 69.4 & 18.5 & $54: 42: 37$ & $.348 * *$ & $.035^{* *}$ & $-.044 * *$ \\
\hline 5 & 0 & & 58 & 17 & 2 & no & no & no & no & no & 10 & 228.9 & 77.6 & 19.9 & $34: 19: 58$ & $.467 * *$ & $.012 * *$ & $-.048 * *$ \\
\hline 6 & 0 & & 46 & 6 & 2 & yes & no & no & no & no & 3 & 229.4 & 73.8 & 15.2 & $55: 27: 58$ & $.478 * *$ & $-.030 * *$ & $-.113 * *$ \\
\hline 7 & 0 & & 41 & 19 & 1 & no & no & no & no & no & 31 & 314.6 & 78.3 & 13.3 & $65: 45: 53$ & $.638 * *$ & $-.174 * *$ & $-.273 * *$ \\
\hline 8 & 1 & & 53 & 20 & 3 & yes & no & no & no & no & 1 & 123.6 & 73.5 & 12.2 & $46: 14: 56$ & $.309 * *$ & $.030 * *$ & $-.079 * *$ \\
\hline 9 & 1 & & 36 & 12 & 4 & no & no & no & no & yes & 27 & 154.9 & 64.4 & 14.3 & $47: 43: 13$ & $.302 * *$ & $.134 * *$ & $.014 * *$ \\
\hline 10 & 1 & & 31 & 6 & 3 & no & no & no & no & no & 14 & 158.8 & 68.5 & 13.5 & $54: 52: 23$ & $.244 * *$ & $.031 * *$ & $-.074 * *$ \\
\hline 11 & 0 & & 34 & 6 & 3 & no & no & yes & no & yes & 15 & 245.0 & 67.8 & 11.5 & $58: 20: 42$ & $.518 * *$ & $.215^{* *}$ & .003 \\
\hline 12 & 1 & & 46 & 20 & 3 & no & no & yes & no & no & 4 & 143.1 & 71.2 & 26.3 & $58: 10: 33$ & $.189 * *$ & $-.010 * *$ & $-.045 * *$ \\
\hline 13 & 0 & & 29 & 8 & 3 & yes & yes & no & yes & yes & 14 & 201.6 & 72.4 & 22.0 & $51: 20: 35$ & $.417 * *$ & $.065^{* *}$ & $-.068 * *$ \\
\hline 14 & 0 & & 23 & 1 & 1 & no & no & no & no & no & 5 & 263.2 & 92.5 & 10.7 & $51: 24: 21$ & $.468 * *$ & $-.034 * *$ & $-.016 * *$ \\
\hline 15 & 0 & & 25 & 4 & 2 & yes & no & no & yes & no & 0 & 253.0 & 76.8 & 18.2 & $42: 24: 37$ & $.536 * *$ & $-.077 * *$ & $-.197 * *$ \\
\hline 16 & 0 & & 37 & 12 & 3 & no & no & no & no & yes & 15 & 246.2 & 70.3 & 14.3 & $55: 50: 15$ & $.527 * *$ & $.169 * *$ & $.048 * *$ \\
\hline 17 & 0 & & 44 & 22 & 3 & no & no & yes & no & no & 6 & 237.2 & 77.7 & 15.0 & $58: 50: 34$ & $.476^{* *}$ & $.014 * *$ & $-.037 * *$ \\
\hline 18 & 0 & & 41 & 20 & 2 & no & no & yes & yes & yes & 4 & 244.0 & 74.8 & 20.7 & $34: 22: 54$ & $.509 * *$ & $.051 * *$ & $.068 * *$ \\
\hline 19 & 1 & & 56 & 25 & 4 & no & yes & no & yes & no & 14 & 124.9 & 67.7 & 11.4 & $53: 39: 46$ & $.196 * *$ & $.051 * *$ & $-.040 * *$ \\
\hline 20 & 1 & & 43 & 20 & 3 & no & no & no & yes & no & 0 & 155.8 & 69.9 & 19.2 & $39: 32: 15$ & $.330 * *$ & $.043 * *$ & $.106 * *$ \\
\hline
\end{tabular}

This is a post-peer-review, pre-copyedit version of an article published in International Archives of Occupational and Environmental Health. The final authenticated version is available online at: http://dx.doi.org/10.1007/s00420-021-01681-3 


\begin{tabular}{|c|c|c|c|c|c|c|c|c|c|c|c|c|c|c|c|c|c|}
\hline 21 & 0 & 31 & 9 & 1 & no & no & no & no & no & 5 & 280.6 & 81.1 & 17.8 & 57:44:09 & $.494 * *$ & $-.111^{* *}$ & $-.172 * *$ \\
\hline 22 & 1 & 29 & 5 & 3 & no & no & yes & no & no & 12 & 150.1 & 77.1 & 16.0 & $67: 40: 21$ & $.218 * *$ & -.003 & $-.109 * *$ \\
\hline 23 & 1 & 50 & 20 & 4 & no & no & no & no & yes & 37 & 135.0 & 69.9 & 14.1 & $49: 19: 22$ & $.269 * *$ & $.035^{* *}$ & $.028 * *$ \\
\hline 24 & 0 & 32 & 10 & 1 & no & no & no & no & no & 1 & 246.6 & 83.1 & 16.8 & $56: 07: 44$ & $.536 * *$ & $-.085^{* *}$ & $-.138 * *$ \\
\hline 25 & 1 & 51 & 26 & 3 & no & no & no & no & no & 5 & 155.9 & 90.6 & 16.6 & $35: 17: 26$ & $.309 * *$ & $.031 * *$ & $-.117 * *$ \\
\hline 26 & 0 & 49 & 26 & 1 & yes & no & no & no & no & 5 & 243.7 & 76.2 & 20.9 & 49:09:47 & $.489 * *$ & $-.112 * *$ & $-.129 * *$ \\
\hline 27 & 0 & 46 & 23 & 3 & no & yes & no & no & yes & 10 & 225.8 & 68.7 & 14.4 & $49: 26: 13$ & $.534 * *$ & $.020 * *$ & $.055^{* *}$ \\
\hline 28 & 0 & 33 & 13 & 1 & no & no & no & no & yes & 12 & 269.7 & 85.9 & 11.1 & $54: 33: 24$ & $.614 * *$ & $-.050^{* *}$ & $-.132 * *$ \\
\hline 29 & 0 & 38 & 13 & 4 & yes & no & no & yes & no & 12 & 216.6 & 60.7 & 16.3 & $57: 45: 41$ & $.528 * *$ & $.021 * *$ & $-.018 * *$ \\
\hline 30 & 0 & 38 & 11 & 2 & no & no & no & yes & yes & 16 & 247.0 & 92.0 & 26.7 & 36:36:51 & $.500 * *$ & $.026 * *$ & $.009 * *$ \\
\hline 31 & 0 & 42 & 19 & 1 & no & no & no & no & no & 5 & 260.1 & 78.4 & 23.3 & 48:53:36 & $.466 * *$ & $-063 * *$ & $-.105^{* *}$ \\
\hline 32 & 0 & 29 & 7 & 1 & no & no & no & no & no & 6 & 239.6 & 73.1 & 13.7 & 72:08:18 & $.469 * *$ & $-.035^{* *}$ & $-.257 * *$ \\
\hline 33 & 0 & 32 & 11 & 3 & no & no & yes & yes & yes & 39 & 255.9 & 79.6 & 16.2 & 64:54:24 & $.611 * *$ & $-.080^{* *}$ & $-.227 * *$ \\
\hline $34^{\mathrm{a}}$ & 0 & 35 & 6 & 3 & no & no & no & yes & no & 7 & 215.5 & 73.7 & 25.1 & 44:40:02 & $.433 * *$ & $-.046^{* *}$ & $-.061 * *$ \\
\hline 35 & 0 & 55 & 14 & 2 & no & no & no & no & no & 2 & 205.8 & 93.7 & 13.7 & $35: 24: 13$ & $.478 * *$ & $.034 * *$ & $-.090 * *$ \\
\hline 36 & 0 & 54 & 33 & 3 & no & no & no & no & no & 8 & 229.6 & 74.8 & 13.2 & $51: 06: 23$ & $.543 * *$ & $-.105^{* *}$ & $-.130 * *$ \\
\hline 37 & 0 & 35 & 11 & 1 & no & no & no & yes & yes & 6 & 244.9 & 82.3 & 16.0 & $50: 02: 33$ & $.524 * *$ & $-.118 * *$ & $-.139 * *$ \\
\hline 38 & 1 & 39 & 10 & 3 & no & no & yes & yes & yes & 11 & 153.7 & 72.0 & 22.07 & $50: 35: 19$ & $.397 * *$ & $.096^{* *}$ & $-.005^{*}$ \\
\hline $39^{\mathrm{a}}$ & 1 & 29 & 9 & 3 & no & no & no & no & yes & 12 & 170.7 & 76.3 & 20.2 & 63:09:12 & $.260 * *$ & .003 & $.032 * *$ \\
\hline 40 & 1 & 49 & 17 & 3 & no & no & no & no & no & 28 & 154.3 & 72.7 & 9.8 & $62: 24: 12$ & $.411 * *$ & $-.064 * *$ & $-.188 * *$ \\
\hline 41 & 0 & 25 & 1 & 3 & no & no & yes & no & no & 13 & 222.6 & 78.7 & 18.6 & 67:38:02 & $.418 * *$ & $-.017 * *$ & $.023 * *$ \\
\hline 42 & 0 & 23 & 3 & 3 & no & no & yes & no & no & 30 & 234.8 & 85.4 & 18.3 & 44:52:44 & $.533 * *$ & $.009 * *$ & $-.030 * *$ \\
\hline 43 & 0 & 30 & 7 & 2 & no & no & no & no & no & 15 & 263.5 & 83.4 & 17.2 & $48: 45: 04$ & $.556 * *$ & $.012 * *$ & $-.061 * *$ \\
\hline 44 & 0 & 31 & 12 & 2 & yes & no & no & no & no & 11 & 254.6 & 80.7 & 13.3 & $49: 35: 32$ & $.515^{* *}$ & $-.088^{* *}$ & $-.116^{* *}$ \\
\hline 45 & 0 & 33 & 10 & 2 & no & no & no & yes & no & 3 & 248.9 & 80.2 & 16.9 & $42: 56: 30$ & $.568 * *$ & $-.012 * *$ & $-.016^{* *}$ \\
\hline 46 & 0 & 41 & 17 & 3 & no & no & no & no & yes & 27 & 234.4 & 73.5 & 18.9 & $55: 56: 44$ & $.427 * *$ & $.027 * *$ & $.124 * *$ \\
\hline 47 & 0 & 28 & 6 & 2 & no & no & no & no & no & 14 & 266.2 & 70.9 & 15.3 & 49:21:54 & $.413 * *$ & $.023 * *$ & $-.096^{* *}$ \\
\hline 48 & 0 & 38 & 14 & 2 & yes & no & no & no & no & 40 & 262.9 & 81.2 & 9.3 & $50: 42: 56$ & $.514 * *$ & $-.027 * *$ & $-.170 * *$ \\
\hline 49 & 0 & 31 & 10 & 1 & no & no & yes & yes & no & 2 & 260.8 & 79.8 & 25.3 & 61:19:27 & $.509 * *$ & $.056^{* *}$ & $-.108^{* *}$ \\
\hline 50 & 1 & 56 & 24 & 4 & no & yes & no & no & no & 8 & 134.9 & 82.0 & 19.6 & $73: 20: 47$ & $.565^{* *}$ & $-.191 * *$ & $-.244 * *$ \\
\hline 51 & 0 & 25 & 5 & 3 & no & no & yes & yes & yes & 37 & 261.8 & 73.8 & 20.1 & 52:02:54 & $.540 * *$ & $.052 * *$ & $.068 * *$ \\
\hline 52 & 0 & 35 & 10 & 1 & no & yes & no & no & yes & 30 & 275.2 & 80.0 & 12.3 & $36: 02: 12$ & $.422 * *$ & $-.120 * *$ & $-.212 * *$ \\
\hline 53 & 0 & 45 & 23 & 1 & no & no & no & no & yes & 7 & 259.9 & 78.7 & 13.2 & $44: 55: 23$ & $.461 * *$ & $-.042 * *$ & $-.021 * *$ \\
\hline 54 & 0 & 48 & 27 & 2 & no & no & no & no & no & 3 & 239.5 & 72.4 & 18.9 & $53: 24: 22$ & $.518 * *$ & $-.048^{* *}$ & $-.071 * *$ \\
\hline 55 & 0 & 51 & 30 & 3 & no & yes & no & no & yes & 6 & 207.1 & 87.8 & 15.6 & 59:13:02 & $.337 * *$ & $.040 * *$ & $-.116^{* *}$ \\
\hline 56 & 0 & 39 & 18 & 1 & no & no & no & no & no & 2 & 264.9 & 74.6 & 24.2 & $42: 21: 37$ & $.529 * *$ & $-.051^{* *}$ & $-.095 * *$ \\
\hline 57 & 0 & 59 & 36 & 3 & no & yes & no & no & no & 1 & 186.6 & 76.7 & 18.1 & 45:12:56 & $.460 * *$ & .002 & $-.087 * *$ \\
\hline 58 & 1 & 49 & 20 & 4 & no & yes & no & yes & yes & 17 & 140.3 & 67.6 & 14.1 & 62:04:08 & $.192 * *$ & $.009 * *$ & $-.193 * *$ \\
\hline 59 & 0 & 53 & 31 & 1 & no & no & yes & no & yes & 7 & 238.7 & 71.0 & 15.9 & $68: 57: 22$ & $.547 * *$ & $-.042 * *$ & $-.183 * *$ \\
\hline 60 & 1 & 24 & 1 & 3 & no & no & no & no & yes & 16 & 135.4 & 60.2 & 6.9 & $38: 57: 55$ & $.332 * *$ & $.065^{* *}$ & $.078 * *$ \\
\hline
\end{tabular}

This is a post-peer-review, pre-copyedit version of an article published in International Archives of Occupational and Environmental Health. The final authenticated version is available online at: http://dx.doi.org/10.1007/s00420-021-01681-3 


\begin{tabular}{|c|c|c|c|c|c|c|c|c|c|c|c|c|c|c|c|c|c|}
\hline 61 & 0 & 36 & 5 & 4 & no & no & no & no & yes & 28 & 219.4 & 70.3 & 23.0 & $65: 17: 24$ & $.498 * *$ & $-.013 * *$ & $-.075 * *$ \\
\hline $62^{a}$ & 0 & 48 & 6 & 3 & no & no & no & no & yes & 5 & 241.5 & 80.1 & 25.9 & $45: 29: 56$ & $.590 * *$ & $-.090 * *$ & $-.094 * *$ \\
\hline 63 & 0 & 33 & 10 & 2 & no & no & no & no & yes & 19 & 261.1 & 72.3 & 18.5 & $51: 29: 50$ & $.545 * *$ & $-.074 * *$ & $-.118 * *$ \\
\hline 64 & 0 & 41 & 20 & 1 & no & no & no & no & no & 0 & 231.9 & 78.4 & 18.4 & $49: 50: 52$ & $.572 * *$ & $-.164 * *$ & $-.228 * *$ \\
\hline 65 & 1 & 44 & 21 & 3 & yes & no & no & yes & no & 14 & 144.5 & 83.4 & 14.8 & $44: 53: 28$ & $.202 * *$ & $.032 * *$ & $.171 * *$ \\
\hline 66 & 0 & 47 & 23 & 1 & no & yes & yes & no & no & 1 & 238.1 & 73.5 & 20.8 & $54: 18: 05$ & $.547 * *$ & $-.086 * *$ & $-.208 * *$ \\
\hline 67 & 0 & 41 & 21 & 2 & no & yes & no & no & no & 10 & 240.5 & 77.7 & 13.2 & $56: 15: 54$ & $.554 * *$ & $-.090 * *$ & $-.071 * *$ \\
\hline 68 & 1 & 54 & 34 & 3 & no & yes & no & yes & no & 5 & 147.7 & 84.7 & 14.5 & $53: 49: 30$ & $.433 * *$ & $.038 * *$ & $-.161 * *$ \\
\hline 69 & 1 & 41 & 17 & 3 & no & no & no & no & no & 7 & 160.4 & 80.5 & 16.2 & $43: 31: 56$ & $.635 * *$ & $.017 * *$ & $.056 * *$ \\
\hline 70 & 0 & 41 & 15 & 4 & no & yes & no & no & yes & 5 & 223.9 & 80.1 & 15.0 & $40: 05: 23$ & $.402 * *$ & $.020 * *$ & $-.019 * *$ \\
\hline 71 & 0 & 46 & 23 & 1 & no & no & no & yes & no & 4 & 268.5 & 74.1 & 13.8 & $59: 50: 55$ & $.615 * *$ & $-.178 * *$ & $-.221 * *$ \\
\hline $72^{\mathrm{a}}$ & 0 & 63 & 33 & 4 & no & no & yes & no & no & 5 & 149.8 & 84.0 & 17.2 & $47: 02: 38$ & $.261 * *$ & $.051 * *$ & $-.033 * *$ \\
\hline 73 & 0 & 36 & 15 & 3 & no & no & yes & no & yes & 18 & 242.5 & 75.2 & 13.2 & $50: 51: 08$ & $.617 * *$ & $.219 * *$ & $.284 * *$ \\
\hline 74 & 0 & 32 & 11 & 3 & no & no & no & yes & no & 7 & 237.9 & 68.7 & 14.1 & $46: 43: 13$ & $.546 * *$ & $-.019 * *$ & $-.093 * *$ \\
\hline 75 & 0 & 44 & 20 & 2 & no & no & no & no & yes & 15 & 266.4 & 77.3 & 17.9 & $47: 00: 20$ & $.516 * *$ & $-.059 * *$ & $-.104 * *$ \\
\hline 76 & 1 & 45 & 20 & 3 & yes & yes & yes & no & yes & 6 & 135.1 & 78.0 & 21.6 & $60: 48: 56$ & $.225 * *$ & $-.033 * *$ & $-.120 * *$ \\
\hline 77 & 0 & 35 & 8 & 4 & no & no & yes & no & no & 1 & 112.8 & 67.3 & 19.2 & $46: 47: 42$ & $.365 * *$ & $.116^{* *}$ & $-.024 * *$ \\
\hline 78 & 0 & 27 & 5 & 3 & no & no & no & no & no & 7 & 234.0 & 71.1 & 15.5 & $57: 14: 49$ & $.488 * *$ & $-.077 * *$ & $-.133 * *$ \\
\hline 79 & 0 & 51 & 30 & 1 & no & yes & yes & no & no & 8 & 246.8 & 70.0 & 21.7 & $62: 33: 43$ & $.496 * *$ & $.049 * *$ & $-.167 * *$ \\
\hline 80 & 0 & 44 & 23 & 1 & no & no & no & no & no & 3 & 229.4 & 78.8 & 15.6 & $65: 08: 29$ & $.505^{* *}$ & $-.022 * *$ & $-.010 * *$ \\
\hline 81 & 0 & 43 & 11 & 1 & no & no & no & no & no & 9 & 265.6 & 81.3 & 14.5 & $54: 57: 38$ & $.556 * *$ & $-.049 * *$ & $-.166 * *$ \\
\hline 82 & 0 & 40 & 17 & 2 & no & no & no & no & no & 40 & 238.7 & 79.8 & 17.5 & $47: 31: 35$ & $.604 * *$ & $-.224 * *$ & $-.237 * *$ \\
\hline 83 & 0 & 47 & 17 & 3 & no & no & no & no & no & 7 & 262.7 & 71.9 & 9.8 & $60: 14: 36$ & $.164 * *$ & $.021 * *$ & $-.252 * *$ \\
\hline 84 & 0 & 39 & 17 & 2 & no & no & no & no & no & 29 & 253.5 & 76.2 & 21.2 & $26: 43: 15$ & $.556 * *$ & $.086 * *$ & $.061 * *$ \\
\hline 85 & 1 & 46 & 11 & 4 & no & no & no & no & no & 13 & 192.8 & 68.0 & 14.3 & $64: 52: 28$ & $.500 * *$ & $.018 * *$ & $-.091 * *$ \\
\hline 86 & 0 & 27 & 4 & 2 & no & no & no & no & no & 4 & 263.8 & 81.6 & 14.0 & $38: 49: 07$ & $.448 * *$ & $-.039 * *$ & .005 \\
\hline 87 & 0 & 27 & 4 & 3 & no & no & no & yes & no & 13 & 242.6 & 73.3 & 19.9 & $44: 54: 52$ & $.566^{* *}$ & $-.065 * *$ & $-.097 * *$ \\
\hline
\end{tabular}

Note. For gender, 0 = female, 1 = male. For teaching level, $1=$ kindergarten, $2=$ elementary, $3=$ secondary, $4=$ university.

${ }^{a}$ Participants who missed one day of recording.

$* \mathrm{p} \leq 0.05$

$* * \mathrm{p} \leq 0.001$ 